\title{
Combinations of Single Chain Variable Fragments From HIV Broadly Neutralizing Antibodies Demonstrate High Potency and Breadth
}

\author{
Rebecca T. van Dorsten ${ }^{1,2}$, Kshitij Wagh ${ }^{3}$, Penny L. Moore ${ }^{1,2,4}$ and Lynn Morris ${ }^{1,2,4^{*}}$ \\ 1 Center for HIV and STIS, National Institute for Communicable Diseases of the National Health Laboratory Service, \\ Johannesburg, South Africa, ${ }^{2}$ Medical Research Council (MRC) Antibody Immunity Research Unit, Faculty of Health \\ Sciences, University of the Witwatersrand, Johannesburg, South Africa, ${ }^{3}$ Theoretical Division, Los Alamos National \\ Laboratory, Los Alamos, NM, United States, ${ }^{4}$ Center for the AIDS Programme of Research in South Africa (CAPRISA), \\ University of KwaZulu-Natal, Durban, South Africa
}

OPEN ACCESS

Edited by:

Susu M. Zughaier, Qatar University, Qatar

Reviewed by:

Christopher Andrew Cottrell,

The Scripps Research Institute, United States

Michael Zwick

The Scripps Research Institute, United States

*Correspondence: Lynn Morris lynnm@nicd.ac.za

Specialty section:

This article was submitted to Vaccines and Molecular Therapeutics,

a section of the journal

Frontiers in Immunology

Received: 30 June 2021

Accepted: 31 August 2021 Published: 16 September 2021

Citation: van Dorsten RT, Wagh K, Moore PL and Morris $L$ (2021) Combinations of Single Chain Variable Fragments

From HIV Broadly Neutralizing Antibodies Demonstrate High Potency and Breadth.

Front. Immunol. 12:734110. doi: 10.3389/fimmu.2021.734110
Broadly neutralizing antibodies (bNAbs) are currently being assessed in clinical trials for their ability to prevent HIV infection. Single chain variable fragments (scFv) of bNAbs have advantages over full antibodies as their smaller size permits improved diffusion into mucosal tissues and facilitates vector-driven gene expression. We have previously shown that scFv of bNAbs individually retain significant breadth and potency. Here we tested combinations of five scFv derived from bNAbs CAP256-VRC26.25 (V2-apex), PGT121 (N332-supersite), 3BNC117 (CD4bs), 8ANC195 (gp120-gp41 interface) and 10E8v4 (MPER). Either two or three scFv were combined in equimolar amounts and tested in the TZM-bl neutralization assay against a multiclade panel of 17 viruses. Experimental $I C_{50}$ and $I C_{80}$ data were compared to predicted neutralization titers based on single scFv titers using the Loewe additive and the Bliss-Hill model. Like full-sized antibodies, combinations of scFv showed significantly improved potency and breadth compared to single scFv. Combinations of two or three scFv generally followed an independent action model for breadth and potency with no significant synergy or antagonism observed overall although some exceptions were noted. The Loewe model underestimated potency for some dual and triple combinations while the Bliss-Hill model was better at predicting $I \mathrm{I}_{80}$ titers of triple combinations. Given this, we used the Bliss-Hill model to predict the coverage of scFv against a 45-virus panel at concentrations that correlated with protection in the AMP trials. Using $\mathrm{IC}_{80}$ titers and concentrations of $1 \mu \mathrm{g} / \mathrm{mL}$, there was 93\% coverage for one dual scFv combination (3BNC117+10E8v4), and 96\% coverage for two of the triple combinations (CAP256.25 $+3 \mathrm{BNC} 117+10 \mathrm{E} 8 \mathrm{~V} 4$ and PGT121+3BNC117+10E8v4). Combinations of scFv, therefore, show significantly improved breadth and potency over individual scFv and given their size advantage, have potential for use in passive immunization.

Keywords: HIV, broadly neutralizing antibodies, single chain variable fragments, combinations of scFv, HIV prevention 


\section{INTRODUCTION}

Broadly neutralizing antibodies (bNAbs), isolated from a subset of $\mathrm{HIV}-1$ positive individuals, are capable of neutralizing a wide range of HIV viruses. Crucially, bNAbs have been shown to provide protection in non-human primate studies and it is thought that such antibodies are needed for an effective HIV vaccine (1-4). However, to date, no candidate HIV vaccines have been able to elicit bNAbs in humans (5-8). This has led the field to actively explore the possibility of using bNAbs as biological drugs for passive immunization against HIV (9-13).

The results of the first efficacy trials of an antibody for HIV prevention tested in Africa and the Americas have recently been published (14-17). These two Antibody-Mediated Prevention (AMP www.ampstudy.org.za) trials showed that VRC01 had $75 \%$ prevention efficacy in high-risk men and women if the infecting virus was sensitive to the antibody at $<1 \mu \mathrm{g} / \mathrm{ml}\left(\mathrm{IC}_{80}\right)$. Therefore, to target the extensive envelope diversity, minimize escape, and provide sufficient potency a combination of multiple antibodies will be needed. Several studies have investigated the potential of antibody combinations and observed, as expected, an increase in breadth and potency $(18,19)$. These studies demonstrate that the complementary neutralization profiles of individual bNAbs can improve the overall breadth and provide higher coverage of multiclade panels of viruses at much lower antibody concentrations $(18,20)$. By using those antibodies that specifically target the HIV subtypes predominant in a specific area, a geographically relevant set of antibodies may be selected to provide optimal coverage and potency (20). For example, CAP256.25, which shows high potency against clade $\mathrm{C}$ viruses, is currently being assessed in combination with PGT121 and VRC07-523LS in dual and triple combination in the South African CAPRISA 012B trial $(21,22)$. Similarly, there are several ongoing phase 1 trials, testing multispecific antibodies or dual and triple combinations. These trials test the aforementioned antibodies in addition to V3 (10-1074) and V2 (PGDM1400) antibodies and the broadly neutralizing MPER-targeting antibody 10E8v4 $(23,24)$.

The ability to accurately predict the breadth and potency of antibody combinations without experimental validation enables the rapid identification of optimal combinations. Two models have been used to predict the $\mathrm{IC}_{50}$ and $\mathrm{IC}_{80}$ of antibody combinations based on single antibody titers, the Loewe Additive model, and the Bliss-Hill Independence model. Both models assume that there is no interaction between the different antibodies and that neutralization by combinations of antibodies will be additive, however, owing to different formulations of independence, their predicted results differ $(18,25)$. These models can also be used to determine whether synergy or antagonism occurs by comparing the predicted data with experimental results. When using the Loewe Additive model most combinations of two antibodies were demonstrated to show additive potency where the experimental potency was close to the predicted $\mathrm{IC}_{50}$ (19). This model in comparison to experimental results has in cases also indicated synergy or antagonism between antibodies targeting specific epitopes such as the CD4 binding site, MPER, and V1/V2 antibodies. However, comprehensive analyses have shown that the Bliss-Hill model tended to be better at predicting IgG combination titers $(18,19)$ and this model did not predict synergy between these epitopes when predictions were compared to experimental results.

Experimental synergy between anti-HIV antibodies has only been rarely observed, and only in the context of bispecific antibodies. A bispecific antibody that simultaneously engaged the V2 and V3 epitopes showed moderate levels of synergy (26). Another bispecific employing a CAP256.25 scFv and the antibody binding fragment (Fab) of 10-1074, showed moderate levels of improved potency against a few viruses (26). In this case, neutralization was compared to single scFv-Fc or IgG rather than to the predicted combination titers or experimental combinations of the two arms, which may have overestimated the level of synergy (20, 26-30). More convincing evidence of synergy was observed when antibodies targeting a host cell protein and the viral Env protein were combined particularly as part of bispecific or trispecific antibody constructs. This effect is due to the localization of the anti-HIV antibody close to the host cell membrane through CCR5 or CD4 binding, for example, the 10E8-iMab, which targets the MPER region on the HIV virion and the CD4 receptor on the HIV target cell. This bispecific antibody has a geometric mean $\mathrm{IC}_{50}$ potency of $0.002 \mu \mathrm{g} / \mathrm{mL}$ compared to $0.4 \mu \mathrm{g} / \mathrm{mL}$ for $10 \mathrm{E} 8$ and $0.05 \mu \mathrm{g} / \mathrm{mL}$ for the iMab indicating a 25 -fold improvement over the expected activity $(27,31)$.

Single chain variable fragments ( $\mathrm{scFv}$ ) are small molecules, which contain the variable heavy and light chain of antibodies connected through a glycine linker. These molecules have some enhanced pharmacokinetic properties such as improved distribution and absorption into mucosal tissues despite a loss of half-life due to lacking an Fc region (32-35). They may also display less steric hindrance when used in combination with other molecules and other bNAbs or scFv (36). This may be especially true for epitopes in close proximity such as the V2 and $\mathrm{V} 3$, or V3 and CD4bs. A recent study demonstrated that scFv targeting the V3 and CD4bs could display synergy when combined with fusion inhibitors (37).

We previously demonstrated that $\mathrm{scFv}$ of bNAbs retain significant breadth and potency against a multiclade panel of viruses despite potency differences linked to differential affinity for the epitope (38). In particular, 10E8v4 maintained the same breadth and most of its potency as an scFv. Single antibodies may be limited in their ability to prevent HIV infection, however, as evidenced by the recent AMP results. We, therefore, tested combinations of $\mathrm{scFv}$ that target major bNAb epitopes on the HIV trimer, namely CAP256.25 (V2 apex), PGT121 (N332supersite), 3BNC117 (CD4bs), 8ANC195 (gp120-gp41), and 10E8v4 (MPER) and show that they generally follow a model of additive potency and complementary breadth. No significant antagonism or synergy was observed compared to the models, although antibody combinations tested against individual viruses could show variation. Overall, combinations of three scFv antibodies reached considerable breadth and potency indicating that $\mathrm{scFv}$ in combinations should be further investigated for passive immunity purposes. 


\section{METHODS}

\section{scFv Construction}

$s c F v$ were designed and cloned previously as described (38). In short, single constructs containing the variable heavy and light chain interspaced with a 15 or 18 amino acid glycine-serine linker of five HIV-directed bNAbs (CAP256.25, PGT121, $3 \mathrm{BNC} 117,8 \mathrm{ANC} 195$, and 10E8v4) were generated through overlapping PCR or ordered from GenScript (New Jersey, USA) (38). These scFv genes were then cloned into a CMV/R expression plasmid (AIDS Reagent Program, Division of AIDS, NIAID, NIH. For the lambda chain of PGT121, the pBR322 based lambda expression vector was used (AIDS Reagent Program, Division of AIDS, NIAID, NIH).

\section{scFv Protein Expression}

The constructs were grown in JM109 bacterial cells and extracted using a plasmid Maxiprep kit (Qiagen, Hilden Germany). Sequences were confirmed using the Applied Biosystems 3500xL Genetic Analyzer. Constructs were expressed as previously described (39). In short, HEK293F suspension cells at $1.5 \times 10^{6}$ to $2 \times 10^{6}$ cells $/ \mathrm{ml}$ were cotransfected with linear Polyethylenimine hydrochloride (molecular weight, 40,000) at a 3:1 ratio with $1 \mu \mathrm{g}$ of plasmid per $1 \mathrm{ml}$ of culture. Supernatants were harvested after 6 days.

scFv proteins were purified using Ni-Sepharose beads (GE Healthcare, Massachusetts USA), washed using a $30 \mathrm{mM}$ imidazole-phosphate-buffered saline (PBS) solution and eluted using $400 \mathrm{mM}$ imidazole in PBS. Glycerol was added to the elution at a final concentration of $5 \%$ to limit aggregation. Eluates were applied to Hiload Superdex 75 or Superdex 200 columns (GE Healthcare) equilibrated with PBS at pH 6.5 (5\% glycerol with $0.02 \%$ sodium azide). The fractions corresponding to the size of the scFv were collected, pooled, and concentrated using Vivaspin concentrators or Vivapore static concentrators (GE Healthcare). The samples were dialyzed overnight at room temperature to remove sodium azide. Concentrations were measured on a NanoDrop device (Thermofisher, MA, USA), with extinction coefficients at $1 \%$ calculated using Expasy ProtParam (40) and characterized by SDS-PAGE. Molar weight was determined by using Expasy ProtParam (CAP256.25: 31.35kDa, PGT121: 28.89kDa, 3BNC117 $28.47 \mathrm{kDa}, 10 \mathrm{E} 8 \mathrm{v} 4: 29.30 \mathrm{kDa}$ and $8 \mathrm{ANC} 19529.00 \mathrm{kDa}) . \mathrm{scFv}$ proteins were stored at $-75^{\circ} \mathrm{C}$.

\section{IgG Production}

IgG constructs were expressed in HEK293F cells as described previously (39). Supernatants were harvested after 6 days and purified using a protein A affinity column. Proteins were eluted using a $0.15 \mathrm{M}$ glycine buffer at $\mathrm{pH} 2.5$ buffer into $1 \mathrm{M}$ Tris, $\mathrm{pH} 8$, and were concentrated and dialyzed into PBS pH 6.5 containing $5 \%$ glycerol. Concentrations were measured on a Nanodrop using an Extinction Coefficient of 13.7 at a $1 \%$ solution. The molecular weight of the IgG was calculated using the Expasy ProtParam (40) of CAP256.25 (150.71kDa), 10E8v4 (147.29kDa), 3BNC117: (146.24kDa), PGT121: (146.2kDa), 8ANC195: (147.43kDa). IgG and proteins were stored at $-75^{\circ} \mathrm{C}$.

\section{Pseudovirus production for TZM-bl Assay}

Plasmids containing HIV-1 envelope (gp160) genes cloned in the $\mathrm{pcDNA}^{\mathrm{TM}} 3.1 \mathrm{D} / \mathrm{V} 5-\mathrm{His}-\mathrm{TOPO}^{\circledR}{ }^{\circledR}$ vector were co-transfected with pSG3 ${ }^{\Delta e n v}$ into HEK293T cells and cultured for $48-72 \mathrm{hrs}$ at $37^{\circ} \mathrm{C}$. Supernatants were harvested and filtered through a $45 \mu \mathrm{m}$ filter and frozen at $-80^{\circ} \mathrm{C}$. Virus stocks were titrated on TZM-bl cells using a luciferase assay to determine a dilution yielding RLU at least 10-fold above the "cell only" background (40,000100,000 RLU).

\section{Neutralization Assay}

A panel of 43 viruses (41) plus BG505 N332 and CAP256_SU (CAP256.3mo.9C) $(42,43)$ representing HIV-1 clades A, B, and $\mathrm{C}$ was used to compare neutralization titers of $\mathrm{IgG}$ and $\mathrm{scFv}$. Neutralization assays were performed in TZM-bl cells as described previously (44-46). Proteins were tested at 200 $\mathrm{gg} /$ $\mathrm{mL}$ for the $\operatorname{IgG}(\sim 146 \mathrm{kDa})$ and $50 \mu \mathrm{g} / \mathrm{mL}$ for the $\mathrm{scFv}(28-32$ $\mathrm{kDa}$ ). All assays were repeated at least twice. $\mathrm{IC}_{50}$ and $\mathrm{IC}_{80}$ of each antibody tested was calculated and geometric mean potency was calculated for both IgG and scFv using sensitive viruses only.

\section{Experimental Testing of scFv Combinations}

Combinations were tested by adding equimolar amounts of two or three scFv proteins in a neutralization assay as described above. A panel of 17 subtype A, B and C viruses were selected based on their sensitivity to at least 2 of the $\mathrm{scFv}$ in order to test neutralization of $\mathrm{scFv}$ combinations and confirm the Loewe Additivity and Bliss-Hill Independence models. Pre-dilutions containing scFv at $2 \mu \mathrm{M}$ and $10 \mu \mathrm{M}$ each were used to facilitate the assay set up. As a control, the single scFv were diluted to $10 \mu \mathrm{M}$ and $2 \mu \mathrm{M}$ as well and run alongside the combinations as a comparison. The highest concentration tested for the combinations was $30 \mu \mathrm{g} / \mathrm{mL}$ or $1000 \mathrm{nM}$. $\mathrm{IC}_{50}$ and $\mathrm{IC}_{80}$ of each experimental antibody combination was calculated, where each antibody is present at the concentration determined at $\mathrm{IC}_{50}$ or $\mathrm{IC}_{80}$.

\section{Loewe Additivity and Bliss-Hill Independence Models}

The $\mathrm{IC}_{50}$ and $\mathrm{IC}_{80}$ values from experimental combinations were compared to the predicted $\mathrm{IC}_{50}$ and $\mathrm{IC}_{80}$ based on the Loewe Additive model and the Bliss-Hill model as previously described $(18,19)$.

The following formula is used to calculate Loewe Additivity.

$$
\text { PredictedIC }_{50}=1 /\left(\frac{1}{I C_{50}(A)}+\frac{1}{I C_{50}(B)}+\ldots \frac{1}{I C_{50}(N)}\right)
$$

Post analysis values were recalculated from $\mathrm{nM}$ into $\mu \mathrm{g} / \mathrm{mL}$ based on the following formula.

$$
I C_{50} \text { in } \mu g / m L=\frac{\left(M w(A) \times I C_{50} \text { in } n M\right)+\left(M w(B) \times I C_{50} \quad \text { in } n M\right)+\ldots\left(M w(N) \times I C_{50} \text { in } n M\right)}{n \times 1000}
$$

Where (n) is the number of antibodies, $\mathrm{Mw}$ the molecular weight of the antibodies in the combination, and $\mathrm{IC}_{50}$ the experimental $\mathrm{IC}_{50}$ or theoretical $\mathrm{IC}_{50}$ obtained. The same formula is used for 
$\mathrm{IC}_{80}$ values replacing the $\mathrm{IC}_{50}$ with $\mathrm{IC}_{80}$ in the formula above. For resistant viruses, the model assumes the titer of the active scFv.

For the Bliss-Hill Independence model, the following formula was used to calculate the Hill function

$$
f(c)=\frac{c^{m}}{\left(k^{m}+c^{m}\right)}
$$

Where $\mathrm{c}=\mathrm{bNAb}$ concentration, $\mathrm{k}=\mathrm{IC}_{50}$, and

$$
m=\frac{\log (4)}{\log \left(I C_{80}\right)-\log \left(I C_{50}\right)}
$$

The combination neutralization curve is then calculated using the Bliss Independence model,

$$
f=1-(1-f(A))(1-f(B))(\ldots)
$$

with $\mathrm{f}(\mathrm{A}), \mathrm{f}(\mathrm{B})$, etc. being the individual functions of the $\mathrm{scFv}$ antibodies. Combination molar $\mathrm{IC}_{50}$ and $\mathrm{IC}_{80}$ titers are calculated by setting $\mathrm{f}=0.5$ or 0.8 and assuming each $\mathrm{scFv}$ is present at the same molarity, and converted to $\mu \mathrm{g} / \mathrm{ml}$ using the above formula.

Dual/triple coverage was calculated by considering a virus resistant if less than $2 / 3$ antibodies in the combination were able to neutralize that virus at set concentrations.

We used the following formula for both models to determine which is more accurate in predicting the combination potencies for $\mathrm{IC}_{50}$ and $\mathrm{IC}_{80}$.

Absolute $\left(\log 10\left(\right.\right.$ experimental $\left.I C_{50}\right)-\log 10\left(\right.$ predicted $\left.\left.I C_{50}\right)\right)$

\section{Synergy and/or Antagonism Predictions Based on Loewe Additivity and Bliss-Hill Independence Models}

Synergy was predicted based on whether the experimental $\mathrm{IC}_{50}$ and $\mathrm{IC}_{80}$ were improved compared to the Loewe Additive model or the Bliss-Hill model. The formula below was used to characterize this effect, with the Bliss-Hill $\mathrm{IC}_{50}$ replacing the Loewe $\mathrm{IC}_{50}$ in the formula below.

$$
\operatorname{LogFold}=\log 10\left(\frac{\text { Loewe }^{50}}{{\text { Experimental } I C_{50}}^{0}}\right)
$$

Positive values indicate experimental titers lower (i.e. more potent) than predicted and imply synergy, while negative values indicate less potent experimental titers than predicted and imply antagonism. For a given combination of antibodies, the mean and the $95 \%$ Confidence interval were calculated using LogFold values for this combination against each virus in the panel.

\section{Statistics}

All statistics were done using the GraphPad Prism 8 software. Fold differences of the experimental combinations were calculated with the most potent $\mathrm{scFv}$ in the mixture for both $\mathrm{IC}_{50}$ and $\mathrm{IC}_{80}$. A Wilcoxon signed-rank test was performed to test which model was more accurate at predicting the experimental titers for both $\mathrm{IC}_{50}$ and $\mathrm{IC}_{80}$. Pearson's Correlation between experimental neutralization titers and titers based on the two models was calculated using the GraphPad software. A nonlinear fit model (log-log) was used to predict the slope between the experimental and predicted data, using a robust regression. A log-fold with a 95\% confidence interval was used to determine if the fold difference is significantly different from 0 , indicating either synergy or antagonism. Breadth-potency curves were drawn using a survival model in GraphPad. Significance was tested using the log-rank Mantel-Cox significance test.

\section{RESULTS}

\section{Dual and Triple Combinations of scFv of HIV bNAbs}

To assess whether scFv of HIV bNAbs showed increased breadth and potency when used in combination, we tested five different $\mathrm{scFv}$ as part of dual and triple combinations. The scFv included those targeting the V2 (CAP256.25), the N332 supersite (PGT121), the CD4bs (3BNC117), and the MPER region $(10 \mathrm{E} 8 \mathrm{v} 4)$, all of which were previously shown to retain significant activity compared to $\operatorname{IgG}$ (38). For this study, we added the antibody 8ANC195 that targets the gp120-gp41 interface so that all five major epitopes on the HIV trimer were covered (see single $\mathrm{IC}_{50}$ and $\mathrm{IC}_{80}$ data in nM Supplementary $\mathbf{1 A}$ and $\mathbf{1 B}$ and in $\mu \mathrm{g} / \mathrm{ml} \mathbf{1 C}$ and $\mathbf{1 D}$ respectively, (38)]. All scFv were expressed and purified by size exclusion columns and, with size and purity confirmed SDS-PAGE gels. scFv were stored in buffers containing $5 \%$ glycerol as determined previously to prevent aggregation (38).

Combinations of $\mathrm{scFv}$ were tested against a panel of 17 pseudoviruses from subtypes $A, B$, and $C(n=3,4$ and 10 , respectively). These were selected based on their sensitivity to at least three of the five scFv under investigation. Equimolar amounts (based on their molecular weights), of each scFv in combinations of two or three were tested, giving a total of 20 different combinations of antibodies (10 dual and 10 triple combinations), which were compared to single scFv neutralization titers. To standardize the output data, the concentration of the single $s c F v$ and the $s c F v$ combinations in $\mu \mathrm{g} / \mathrm{mL}$ were calculated from the $\mathrm{nM}$ titers and the molecular weight of the scFvs (Figure 1, Supplementary Figure 2) (38). Combination titers $\mathrm{IC}_{50}$ and $\mathrm{IC}_{80}$ are reported as the concentration of each $\mathrm{scFv}$ in the mix in $\mu \mathrm{g} / \mathrm{mL}$ or $\mathrm{nM}$.

As expected, combinations of two $s c F v$ improved the coverage, with active scFv making up for the inactive scFv. For all dual and triple combinations, breadth reached $100 \%$ at $\mathrm{IC}_{50}$ against this 17 -virus panel (Figure 1). The neutralization of individual viruses by two or three $\mathrm{scFv}$ was usually similar to the $\mathrm{IC}_{50}$ of the most potent $\mathrm{scFv}$ in the combination (Figure 1; fold differences are shown in the columns next to the $\mathrm{IC}_{50} \mathrm{~s}$ ). Except for a few cases, the virus neutralization titers of the dual and triple combinations fell within 3 -fold of the titer of the 


\begin{tabular}{|c|c|c|c|c|c|c|c|c|c|c|c|c|c|c|c|c|c|c|c|c|c|}
\hline \multicolumn{12}{|c|}{ A } & \\
\hline & & \multicolumn{10}{|c|}{$\mathrm{IC}_{50}$ of single scFv in $\mu \mathrm{g} / \mathrm{mL}$ (converted from $\mathrm{nM}$ ) } & & & & & & & & & & \\
\hline \multicolumn{2}{|c|}{ Pseudovirus } & \multirow{2}{*}{\multicolumn{2}{|c|}{$\begin{array}{c}\text { CAP256.25 } \\
0.30\end{array}$}} & \multirow{2}{*}{\multicolumn{2}{|c|}{$\begin{array}{c}\text { PGT121 } \\
0.0054\end{array}$}} & \multirow{2}{*}{\multicolumn{2}{|c|}{ 3BNC117 }} & 8ANC & 195 & 10E8 & & & & & & & & & & & \\
\hline 0 & Q23 & & & & & & & 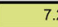 & & 0.4 & & & & & & & & & & & \\
\hline$\sum_{0}^{2}$ & Q168 & 1.1 & & $>3$ & & 0.03 & & 0.6 & & 0.5 & & & & & & & & & & & \\
\hline 莺 & Q842 & 3.7 & & 0.0 & & 0.0 & & $>3$ & & 0.5 & & & & & & & & & & & \\
\hline$\infty$ & AC10 & 7.3 & & 0.0 & & $>3$ & & 1. & & 0.1 & & & & & & & & & & & \\
\hline 。 & RHPA & $>3 c$ & & 0.0 & & 0.0 & & 0.2 & & 0.3 & & & & & & & & & & & \\
\hline 吾 & PV04 & 0.8 & & 0.1 & & 0.04 & & 1. & & 0.6 & & & & & & & & & & & \\
\hline & 6535 & $>30$ & & 0.00 & & 5.4 & & 0.5 & & 0.1 & & & & & & & & & & & \\
\hline & Du156 & 0.01 & & 0.0 & & 1.5 & & 2. & & 0.1 & & & & & & & & & & & \\
\hline & ZM53 & 0.00 & & 0.0 & & 1.7 & & 0.1 & & 0.3 & & & & & & & & & & & \\
\hline & ZM233 & 0.04 & & $>3$ & & 4.2 & & 2. & & 0.10 & & & & & & & & & & & \\
\hline 0 & ZM249 & 0.5 & & 0.3 & & 0.0 & & 8. & & 0.4 & & & & & & & & & & & \\
\hline 잋 & CAP8.6F & 8.1 & & 0.00 & & $>3$ & & 2. & & 0.1 & & & & & & & & & & & \\
\hline 章 & CAP61 & 4.5 & & 0.0 & & 2.7 & & 13 & & 0.3 & & & & & & & & & & & \\
\hline & CAP84.32 & 9.2 & & 0.00 & & $>3$ & & $>3$ & & 0.3 & & & & & & & & & & & \\
\hline & CAP88 & $>3$ & & 4. & & 28 & & 5 . & & 0.00 & & & & & & & & & & & \\
\hline & CAP256_SU & 0.00 & & 0.0 & & 0.4 & & 0.2 & & 0.6 & & & & & & & & & & & \\
\hline & Conc & 0.00 & & 0.0 & & 2. & & 1. & & 0.1 & & & & & & & & & & & \\
\hline & Geomean & 0.2 & & 0.0 & & 0.4 & & 1. & & 0.2 & & & & & & & & & & & \\
\hline B & & & & & & & & & & & & & & & & & & & & & \\
\hline & & & & & & & & 50 of $\mathrm{Co}$ & mbina & tions of & ScFvi & $\mathrm{n} \mu \mathrm{g} / \mathrm{mL}$ & (con & verted fr & rom $\mathrm{nl}$ & & & & & & \\
\hline & seudovirus & $\begin{array}{r}\text { CAP25 } \\
\text { PGT1 }\end{array}$ & \begin{tabular}{|l|}
6.25 \\
21
\end{tabular} & $\begin{array}{r}\text { CAP25 } \\
3 B N C \\
\end{array}$ & & $\begin{array}{l}\text { CAP25 } \\
\text { 8ANC }\end{array}$ & $\begin{array}{l}6.25 \\
195\end{array}$ & $\begin{array}{r}\text { CAP25 } \\
10 \mathrm{ES} \\
\end{array}$ & $\begin{array}{l}6.25 \\
\mathrm{v} 4 \\
\end{array}$ & $\begin{array}{l}\mathrm{PGT1} \\
\text { 3BNC }\end{array}$ & & $\begin{array}{l}\text { PGT } \\
\text { 8ANC }\end{array}$ & & $\begin{array}{l}\text { PGT1 } \\
\text { 10E8 }\end{array}$ & & $\begin{array}{l}\text { 3BNC } \\
\text { 8ANC }\end{array}$ & & $\begin{array}{r}3 B N C \\
10 E 8 \\
\end{array}$ & & $\begin{array}{l}8 \mathrm{ANC} \\
10 \mathrm{E}\end{array}$ & \\
\hline \begin{tabular}{|l|}
$<$ \\
0
\end{tabular} & Q23 & 0.0074 & 0.7 & 0.028 & 1.5 & 0.18 & 1.7 & 0.058 & 5.2 & 0.0065 & 0.8 & 0.0076 & 0.7 & 0.0091 & 0.6 & 0.046 & 0.9 & \begin{tabular}{|l|}
0.042 \\
\end{tabular} & 1.0 & 0.44 & 1.0 \\
\hline 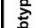 & Q168 & 1.1 & 1.0 & 0.028 & 1.1 & 0.29 & 2.3 & 0.14 & 3.5 & 0.031 & 1.0 & 0.97 & 0.7 & 0.46 & 1.1 & 0.025 & 1.2 & 0.024 & 1.2 & 0.20 & 2.6 \\
\hline $\begin{array}{l}0 \\
\text { के } \\
\end{array}$ & Q842 & 0.041 & 1.4 & 0.0078 & 1.5 & 2.1 & 1.7 & 0.39 & 1.4 & 0.0064 & 1.8 & 0.043 & 1.3 & 0.030 & 2.0 & 0.0084 & 1.4 & 0.0078 & 1.5 & 0.52 & 1.0 \\
\hline$\infty$ & AC10 & 0.042 & 1.0 & 18 & 0.4 & 1.1 & 1.7 & 0.093 & 1.1 & 0.033 & 1.3 & 0.044 & 1.0 & 0.016 & 2.6 & 2.7 & 0.7 & 0.11 & 1.0 & 0.10 & 1.0 \\
\hline 岁 & RHPA & 0.029 & 0.4 & 0.013 & 1.2 & 0.22 & 1.1 & 0.20 & 1.8 & 0.012 & 1.1 & 0.025 & 0.5 & 0.027 & 0.5 & 0.023 & 0.7 & 0.024 & 0.7 & 0.16 & 1.6 \\
\hline$\frac{\overrightarrow{0}}{3}$ & PV04 & 0.16 & 1.0 & 0.034 & 1.3 & 0.30 & 2.8 & 0.16 & 4 & 0.036 & 1.2 & 0.083 & 1.9 & 0.11 & 1.5 & 0.034 & 1.3 & 0.032 & 1.4 & 0.24 & 2.7 \\
\hline & 6535 & 0.0032 & 1.1 & 7.0 & 0.8 & 0.31 & 1.8 & 0.080 & 2.0 & 0.0035 & 1.0 & 0.0040 & 0.9 & 0.0033 & 1.0 & 0.26 & 2.1 & 0.11 & 1.5 & 0.086 & 1.9 \\
\hline & Du156 & 0.011 & 1.4 & 0.011 & 1.4 & 0.012 & 1.2 & 0.0096 & 1.5 & 0.012 & 1.2 & 0.012 & 1.2 & 0.0071 & 2.1 & 0.52 & 2.8 & 0.071 & 1.6 & 0.069 & 1.7 \\
\hline & ZM53 & 0.0039 & 0.5 & 0.0040 & 0.5 & 0.0035 & 0.6 & 0.0039 & 0.5 & 0.083 & 0.8 & 0.049 & 1.3 & 0.028 & 2.3 & 0.16 & 1.0 & 0.28 & 1.2 & 0.28 & 0.6 \\
\hline & ZM233 & 0.025 & 1.2 & 0.017 & 1.8 & 0.026 & 1.2 & 0.014 & 2.2 & 2.9 & 1.0 & 3.7 & 0.7 & 0.12 & 0.8 & 1.4 & 1.8 & 0.18 & 0.6 & 0.13 & 0.8 \\
\hline 0 & ZM249 & 0.26 & 1.3 & 0.043 & 1.5 & 0.99 & 0.5 & 0.045 & 9 & 0.21 & 0.3 & 0.67 & 0.5 & 0.091 & $\begin{array}{ll}3.7 \\
\end{array}$ & 0.076 & 0.9 & \begin{tabular}{l|}
0.068 \\
\end{tabular} & 1.0 & 0.31 & 1.3 \\
\hline ळ & CAP8.6F & 0.0083 & 1.2 & 4.3 & 1.9 & 1.5 & 2.0 & 0.069 & 2.5 & 0.0087 & 1.1 & 0.0076 & 1.3 & 0.0082 & 1.2 & 3.6 & 0.8 & 0.24 & 0.7 & 0.15 & 1.1 \\
\hline 苛 & CAP61 & 0.013 & 1.4 & 0.82 & 3.2 & 1.5 & 3.1 & 0.10 & 3.1 & 0.016 & 1.2 & 0.012 & 1.6 & 0.012 & 1.6 & 2.5 & 1.1 & 0.22 & 1.5 & 0.17 & 1.9 \\
\hline & CAP84.32 & 0.0051 & 0.8 & 9.6 & 1.0 & 11 & 0.8 & 0.16 & 2.1 & 0.0041 & 1.0 & 0.0050 & 0.8 & 0.0043 & 0.9 & 6.9 & 4.3 & 0.25 & 1.3 & 0.31 & 1.1 \\
\hline & CAP88 & 2.0 & 2.3 & 30 & 1.0 & 4.6 & 1.1 & 0.0089 & 1.1 & 4.1 & 1.1 & 0.15 & 29 & 0.0052 & 1.9 & 9.6 & 0.5 & 0.0092 & 1.1 & 0.011 & 0.9 \\
\hline & CAP256_SU & 0.0041 & 0.6 & 0.0050 & 0.5 & 0.0038 & 0.6 & 0.0048 & 0.5 & 0.018 & 1.0 & 0.018 & 1.0 & 0.014 & 1.3 & 0.12 & 2.3 & 0.21 & 2.0 & 0.28 & 1.0 \\
\hline & Conc & 0.0047 & 1.2 & 0.0075 & 0.7 & 0.0093 & 0.6 & 0.0099 & 0.5 & 0.0073 & 2.2 & 0.0063 & 2.6 & 0.0059 & 2.8 & 0.38 & 2.8 & 0.087 & 2.0 & 0.076 & 2.3 \\
\hline & Geomean & 0.026 & 1.2 & 0.12 & 2.2 & 0.23 & 1.2 & 0.044 & 4.9 & 0.030 & 1.1 & 0.040 & 0.80 & 0.019 & 1.6 & 0.30 & 1.3 & 0.072 & 3.0 & 0.16 & 1.4 \\
\hline$\overline{\mathbf{C}}$ & & & & & & & & & & & & & & & & & & & & & \\
\hline & & & & & & & & $\mathrm{C}_{50} \mathrm{Com}$ & binati & ons of $s$ & $\mathrm{cFv}$ in & $\mu \mathrm{g} / \mathrm{mL}$ & (conv & erted fro & $\mathrm{m} \mathrm{nM}$ & & & & & & \\
\hline & seudovirus & $\begin{array}{l}\text { CAP25 } \\
\text { PGT1 } \\
\text { 3BNC }\end{array}$ & $\begin{array}{l}6.25 \\
21 \\
117\end{array}$ & $\begin{array}{r}\text { CAP2 } \\
\text { PGT } \\
\text { 8ANC }\end{array}$ & & $\begin{array}{c}\text { CAP2 } \\
\text { PGT } \\
10 E 8\end{array}$ & $\begin{array}{l}56.25 \\
121 \\
1 \mathrm{v} 4\end{array}$ & $\begin{array}{l}\text { CAP2 } \\
\text { 3BNC } \\
\text { 8ANC }\end{array}$ & \begin{tabular}{|l|}
6.25 \\
117 \\
195
\end{tabular} & $\begin{array}{r}\text { CAP25 } \\
\text { 3BNC } \\
1088\end{array}$ & \begin{tabular}{|l|}
6.25 \\
117 \\
v4 \\
\end{tabular} & $\begin{array}{l}\text { CAP2 } \\
\text { 8ANC } \\
10 E 8\end{array}$ & $\begin{array}{l}6.25 \\
195 \\
v 4\end{array}$ & $\begin{array}{l}\text { PGT1 } \\
\text { 3BNC } \\
\text { 8ANC }\end{array}$ & & $\begin{array}{r}\text { PGT } \\
\text { 3BNC } \\
10 \mathrm{~EB}\end{array}$ & & $\begin{array}{r}\text { PGT1 } \\
\text { 8ANC } \\
\text { 10E8 }\end{array}$ & & $\begin{array}{l}\text { 3BN } \\
\text { 8ANC } \\
\text { 10E }\end{array}$ & \\
\hline 0 & Q23 & 0.003 & 1.9 & 0.004 & 1.5 & 0.003 & 1.8 & 0.023 & 1.8 & 0.022 & 1.9 & 0.075 & 4.1 & 0.006 & 1.0 & 0.005 & 1.1 & \begin{tabular}{l|}
0.005 \\
\end{tabular} & 1.2 & 0.045 & 0.9 \\
\hline$\sum_{2}^{2}$ & Q168 & \begin{tabular}{|l|}
0.031 \\
\end{tabular} & 1.0 & 0.28 & 2.4 & 0.16 & 3.1 & 0.021 & 1.5 & 0.016 & 1.9 & 0.093 & 5.5 & 0.033 & \begin{tabular}{|l|}
0.9 \\
\end{tabular} & 0.023 & 1.3 & 0.13 & 3.9 & 0.029 & 1.0 \\
\hline 今े & Q842 & 0.007 & 1.8 & 0.040 & 1.5 & 0.046 & 1.3 & 0.008 & 1.5 & 0.008 & 1.4 & 0.38 & 1.4 & 0.006 & 2.0 & 0.006 & 2.1 & \begin{tabular}{|l|}
0.023 \\
\end{tabular} & 2.5 & 0.008 & 1.5 \\
\hline$\infty$ & AC10 & 0.028 & 1.5 & 0.024 & $\begin{array}{ll}1.7 \\
\end{array}$ & 0.030 & 1.4 & 1.9 & 0.9 & 0.051 & 2.0 & 0.046 & 2.2 & 0.041 & 1.0 & 0.022 & 1.9 & 0.021 & 2.0 & 0.061 & 1.7 \\
\hline 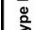 & RHPA & \begin{tabular}{|l|}
0.005 \\
\end{tabular} & 2.6 & 0.008 & 1.6 & 0.025 & 0.5 & 0.014 & 1.1 & 0.011 & 1.5 & 0.095 & 2.6 & \begin{tabular}{l|}
0.007 \\
\end{tabular} & 1.7 & 0.007 & 1.7 & \begin{tabular}{|l|}
0.006 \\
\end{tabular} & 2.1 & 0.015 & 1.1 \\
\hline 常 & PV04 & \begin{tabular}{|l|}
0.025 \\
\end{tabular} & 1.7 & 0.074 & 2.1 & 0.12 & 1.3 & 0.038 & 1.2 & 0.023 & 1.9 & 0.100 & 6.5 & 0.034 & \begin{tabular}{|l|}
1.3 \\
\end{tabular} & 0.029 & 1.5 & \begin{tabular}{|l|}
0.075 \\
\end{tabular} & 2.1 & 0.035 & 1.2 \\
\hline & 6535 & 0.002 & 1.7 & 0.002 & 1.7 & 0.003 & 1.0 & 0.39 & 1.4 & 0.079 & 2.1 & 0.082 & 2.0 & 0.005 & 0.7 & 0.004 & 0.9 & 0.003 & 1.0 & 0.081 & 2.0 \\
\hline & $\begin{array}{l}\text { Du156 } \\
\end{array}$ & \begin{tabular}{|l|}
0.004 \\
\end{tabular} & $\begin{array}{l}3.7 \\
\end{array}$ & 0.003 & 4.5 & 0.004 & 3.7 & 0.029 & 0.5 & 0.009 & $\begin{array}{l}1.6 \\
\end{array}$ & 0.010 & 1.5 & 0.008 & 1.9 & 0.007 & 2.0 & 0.005 & 3.1 & 0.084 & 1.4 \\
\hline & ZM53 & 0.001 & 1.7 & 0.002 & 1.3 & 0.002 & 1.2 & 0.002 & 0.8 & 0.001 & 1.4 & 0.002 & 1.3 & 0.045 & 1.5 & 0.047 & 1.4 & \begin{tabular}{l|}
0.032 \\
\end{tabular} & 2.0 & 0.090 & 1.7 \\
\hline & ZM233 & \begin{tabular}{|l|}
0.068 \\
\end{tabular} & 0.5 & 0.050 & $\begin{array}{l}0.6 \\
\end{array}$ & 0.023 & 1.3 & 0.048 & 0.7 & 0.023 & 1.4 & 0.018 & 1.8 & 1.9 & 1.3 & 0.18 & 0.5 & 0.10 & 1.0 & 0.15 & 0.7 \\
\hline 0 & ZM249 & 0.032 & 2.0 & 0.15 & 2.2 & 0.074 & 4.5 & 0.063 & 1.0 & 0.013 & 4.9 & 0.063 & 6.3 & 0.15 & \begin{tabular}{|l|l|}
0.4 \\
\end{tabular} & 0.054 & 1.2 & 0.11 & 3.2 & 0.068 & 1.0 \\
\hline ळ & CAP8.6F & \begin{tabular}{|l|}
0.010 \\
\end{tabular} & 1.0 & 0.007 & 1.5 & 0.006 & 1.7 & 3.0 & 1.0 & 0.11 & 1.5 & 0.077 & 2.3 & 0.013 & 0.7 & 0.011 & 0.9 & 0.006 & 1.6 & 0.11 & 1.5 \\
\hline$\frac{\overrightarrow{0}}{3}$ & CAP61 & 0.016 & 1.2 & 0.010 & 1.8 & 0.008 & 2.4 & 1.3 & 2.0 & 0.15 & 2.2 & 0.11 & 2.9 & 0.015 & 1.3 & 0.013 & 1.5 & 0.007 & 2.7 & 0.24 & 1.3 \\
\hline 0 & $\begin{array}{l}\text { CAP84.32 } \\
\end{array}$ & \begin{tabular}{|l|l|}
0.003 \\
\end{tabular} & 1.3 & 0.003 & 1.2 & 0.007 & 0.6 & 3.8 & 2.4 & 0.20 & 1.7 & 0.18 & 1.9 & 0.006 & \begin{tabular}{|l|l|}
0.7 \\
\end{tabular} & 0.004 & 1.0 & 0.005 & 0.9 & 0.15 & 2.3 \\
\hline & CAP88 & 1.9 & 2.0 & 0.58 & $\begin{array}{ll}6.7 \\
\end{array}$ & 0.004 & 2.2 & 1.4 & 3.5 & 0.003 & 3.6 & 0.002 & 5.4 & 1.3 & 2.9 & 0.005 & 1.9 & 0.004 & 2.5 & 0.004 & 2.6 \\
\hline & CAP256_SU & 0.002 & 1.2 & 0.004 & 0.5 & 0.002 & 1.0 & 0.003 & 0.9 & 0.003 & 0.8 & 0.002 & 1.0 & 0.022 & 0.9 & 0.012 & 1.6 & 0.013 & 1.4 & 0.098 & 2.8 \\
\hline & Conc & $\begin{array}{ll}0.003 \\
\end{array}$ & 2.1 & 0.002 & 2.7 & 0.003 & 1.9 & 0.008 & 0.7 & 0.006 & 0.9 & 0.006 & 0.9 & 0.009 & 1.8 & 0.008 & 2.1 & \begin{tabular}{|l|}
0.008 \\
\end{tabular} & 1.9 & 0.048 & 3.6 \\
\hline & Geomean & 0.010 & 3.0 & 0.014 & 2.2 & 0.011 & 2.8 & 0.078 & 3.5 & \begin{tabular}{|l|}
0.018 \\
\end{tabular} & 12 & 0.033 & 6.6 & \begin{tabular}{l|l|}
0.027 \\
\end{tabular} & 1.2 & 0.013 & 2.4 & \begin{tabular}{|l|}
0.015 \\
\end{tabular} & 2.1 & 0.052 & 4.2 \\
\hline
\end{tabular}

FIGURE 1 | Neutralization titers of single, dual, and triple combinations of scFv. Heat map showing $\mathrm{IC}_{50}$ neutralization titers in $\mu \mathrm{g} / \mathrm{mL}$ for single (A), dual (B), and triple (C) combinations of scFv against a panel of 17 subtype A, B, and C viruses. Viruses insensitive to individual bNAbs are shown as $>30 \mu \mathrm{g} / \mathrm{mL}$. The fold improvement in $\mathrm{IC}_{50}$ titers of the dual and triple combinations relative to the $\mathrm{IC}_{50}$ of the best scFv in the combination is included in (B, $\left.\mathbf{C}\right)$. Values with $>3$-fold increase or decrease in neutralization are shown in bold. Geometric mean potency is included at the bottom of each table. Each scFv is present in the combination at the titer indicated. 
most potent single scFv in that combination. There was little to no loss of potency noted compared to the most potent scFv for the entire panel for all $20 \mathrm{scFv}$ combinations tested (a total of 340 single test titers). A few instances of potential gain of potency compared to the most potent scFv were noted, with most of these linked to specific scFv combinations (bolded values in Figure 1).(See Supplementary Figure 2 for $\mathrm{IC}_{50}$ titers in $\mathrm{nM}(\mathbf{A})$ and $\mu \mathrm{g} / \mathrm{mL}$ (B) and for $\mathrm{IC}_{80}$ values in $\mathrm{nM}(\mathbf{C})$ and $\mu \mathrm{g} / \mathrm{mL}$ (D) respectively).

The combination of CAP256.25+10E8v4 scFv stood out, demonstrating an overall 4.9-fold improvement in geometric mean titer (Figure 1B). This was driven by five viruses of which two were subtype A, one was subtype $B$ and two were subtype $C$ indicating this was not subtype-specific. Five other dual $\mathrm{scFv}$ combinations showed improved potency over single $s c F v$ for single viruses but this was not linked to any specific combination of antibodies. The 3BNC117+10E8v4 combination showed an overall significant improvement in the geometric mean titer although this was not seen for individual viruses indicating complementarity of neutralization potency of the $s c F v$ rather than synergy.

For the triple combinations, five of the ten combinations showed $>3$-fold improved geometric means compared to the most potent single $s c F v$ with a 12 -fold improvement for the CAP256.25+3BNC117+10E8v4 combination (Figure 1C). This was higher than for the dual combinations where only two out of ten showed an improvement in geometric mean potency and was driven by improvement in potency against single viruses (16 of the 170 virus-scFv combination pairings). This was due to the scFv (e.g. CAP256.25 and 3BNC117 scFv), in the combinations being potent against different viruses allowing for complementarity in neutralization potency and coverage. Triple combinations overall showed higher improvements in breadth compared to dual combinations or single $\mathrm{scF}$ as a consequence of having more antibodies.

Some viruses appeared to be more sensitive to the effects of combined scFv. For example, a slight potency improvement was observed against the CAP61 and ZM249 viruses for the dual combinations, although for the latter loss of potency was also noted (fold difference $<0.33$ see Figure 1B). Some enhancement in potency was also seen with these viruses plus Du156 and CAP88 for the triple combinations (Figure 1C).

Overall, we found either improved or similar titers for combinations compared to the most potent single scFv, particularly for triple combinations, indicating that combinations of scFv improve the coverage of a panel of viruses and the potency at which viruses are neutralized. We overlaid neutralization curves of the combinations with the single scFv used in the combination, to determine if there were distinct patterns associated with improved $\mathrm{IC}_{50} \mathrm{~s}$ or where we observed similar $\mathrm{IC}_{50}$ for the combinations compared to the single scFv. For most dual and triple combinations (314/340), an additive effect was seen where the combination curve overlapped with the best scFv in the combination (Figure 2A). Here $\mathrm{IC}_{50}$ did not show a potency improvement compared to the single scFv. A few combinations shifted the curve to the left compared to the curve of the most potent single scFv corresponding with fold potency improvements as seen in Figure $\mathbf{1}$ and indicating potential synergy (10/170 virus-dual combination pairings and $16 / 170$ in the triple combinations showed improved $\mathrm{IC}_{50} \mathrm{~s}$ ) (Figure 2B). In one case we observed decreased potency for the combination compared to the most potent $\mathrm{scFv}$ possibly indicating some antagonism (Figure 2C). With the addition of a third antibody this was partially negated (Figure 2C right panel). Overall, most combinations did not show significant potency improvements or loss of potency, suggesting that they largely followed an additive model of potency.

\section{scFv Follow an Additive Model of Interaction in HIV Neutralization}

To further explore whether combinations of $\mathrm{scFv}$ follow an additive model of interaction we compared the experimental results with predictions based on the single $s c F v$ titers using the Loewe Additive model and the Bliss-Hill models. As mentioned before, both these models assume no synergistic or antagonistic interactions between antibodies $(18,19)$. We calculated the combination $\mathrm{scFv} \mathrm{IC}_{50}$ and $\mathrm{IC}_{80}$ titers based on these 2 models (Methods) and based on the geometric mean $\mathrm{IC}_{50}$ and $\mathrm{IC}_{80}$ of the repeats of single $\mathrm{scFv}$ obtained in the experiment. All scFv predicted data titers were compared to the $\mathrm{IC}_{50}$ and $\mathrm{IC}_{80}$ titers of the experimentally tested combinations.

There was a strong significant $(\mathrm{p}<0.0001)$ correlation between the experimental $\mathrm{IC}_{50}$ and $\mathrm{IC}_{80}$ and the predicted $\mathrm{IC}_{50}$ and $\mathrm{IC}_{80}$ of the dual combinations for both the Loewe and Bliss Hill model (Loewe, Pearson's $r=0.94$ and $\mathrm{r}=0.79$ respectively, Bliss-Hill, $\mathrm{r}=0.94$ and 0.91 respectively) (Figures 3A, B). Similarly, for the triple combinations, there was a strong correlation between the predicted values and the experimental values (Loewe $r=0.78$ and $r=0.79$, Bliss-Hill: $r=0.70$ and $\mathrm{r}=0.95$ respectively) (Figures 3C, D). For each combination, we also determined which model was better by comparing the mean absolute log difference between the experimental values and the predicted values for each individual combination. For the dual combinations, the Bliss Hill model was better at predicting two out of the 10 combinations (10E8v4 combined with CAP256.25 or PGT121), whereas no significant difference between the models was observed for any of the other combinations (Figures 3E, F). Similarly, for the triple combinations, most combinations did not show differences between the two models in the $\mathrm{IC}_{50}$ with the BlissHill model being better at predicting two combinations (8ANC195 $+10 \mathrm{E} 8 \mathrm{v} 4$ with either CAP256.25 or PGT121) (Figure 3G). For the $\mathrm{IC}_{80}$ of the triple combinations, 6/10 combinations were significantly better predicted by the Bliss-Hill model compared to the Loewe model (Figure $\mathbf{3 H}$ ). This indicated that for most combinations both Loewe and Bliss-Hill could predict combination $\mathrm{IC}_{50}$ titers well with a slight advantage for the BlissHill model. However, the Bliss-Hill model is significantly better at predicting triple $\mathrm{IC}_{80}$ titers compared to the Loewe model, with the latter underestimating the potency of the triple combinations at $\mathrm{IC}_{80}$. 
A

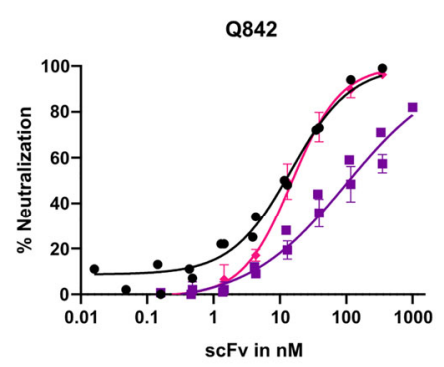

B

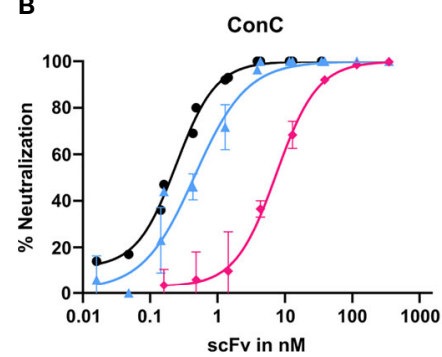

C

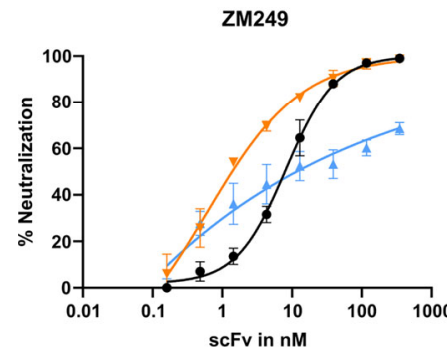

Additive Potency

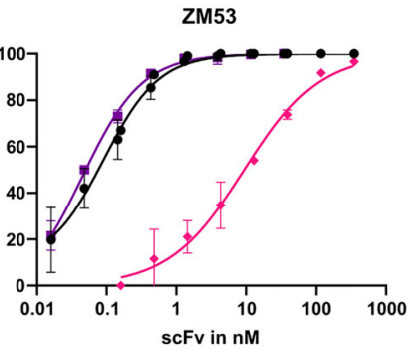

Synergy

CAP61

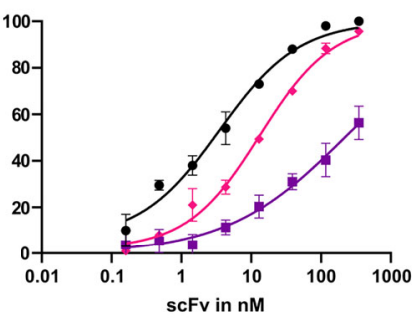

Antagonism

ZM249

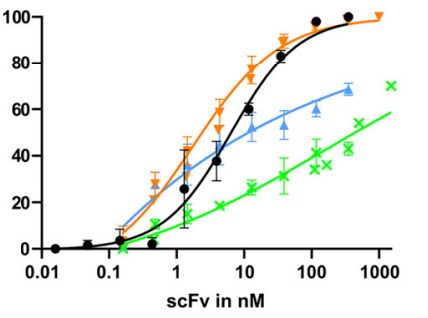

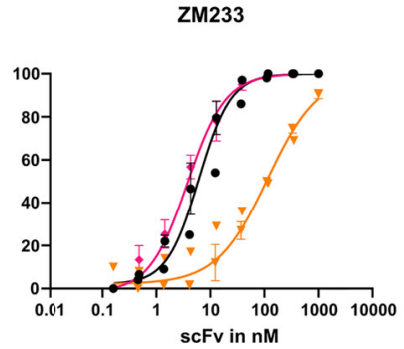

CAP88

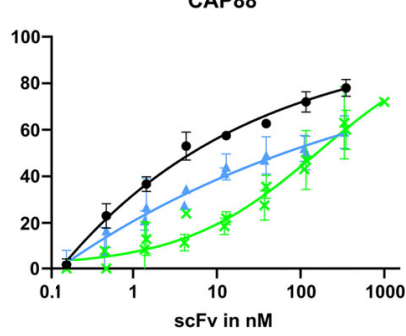

- Combination

$\rightarrow$ CAP256.25

- PGT121

- 3BNC117

* 8ANC195

$\rightarrow$ 10E8v4

FIGURE 2 | Combinations of scFv that show improved neutralization potency over single scFv. Neutralization curves showing potential additive, synergistic and antagonistic potency effects of combinations of antibodies. Combinations of scFv compared to single scFv neutralization curves with CAP256.25 in purple, PGT121 in light blue, 3BNC117 in orange, 8ANC195 in green and 10E8v4 in pink. The dual or triple combinations are represented in black. Geometric mean values are used for each data point with error bars representing repeat experiments. (A) Examples of combinations where neither synergy nor antagonism is observed for three viruses tested against dual combinations of scFv. Additive potency is represented by the combination curve (black) overlapping with the best scFv in the mixture. (B) Potential synergy as observed in dual combinations of scFv against three different virus strains. Synergy was represented by a left shift of the combination curve (black) relative to the most potent scFv in the mixture, or by steeper neutralization curves resulting in improved IC80. (C) Potential antagonism as represented by a right shift of the combination curve relative to the most potent scFv in the mixture, observed in combinations of two or three scFv tested against ZM249, which was sensitive to all ScFv in the combinations.

\section{No Synergy or Antagonism Observed for scFv Combinations Against a Panel of HIV Pseudovirus}

We next sought to determine if any of the combinations showed significant potency improvement or potency loss in either $\mathrm{IC}_{50}$ or $\mathrm{IC}_{80}$ by comparing the experimental data to the expected titers based on the Bliss Hill model. These analyses allowed us to determine if there is potential synergy (higher potency than predicted), as indicated by a log-fold difference $>0.4$ ( $\sim 2.5$ fold $)$ and/or antagonism (lower potency than predicted) as indicated by a log-fold difference $<-0.4$ (Figure 4 ). The dual combinations had a mean log-fold difference close to 0 (log-fold $-0.4<\mathrm{CI}<0.4$ ) for both $\mathrm{IC}_{50}$ and $\mathrm{IC}_{80}$ indicating that there was neither antagonism nor synergy, although a few antibody combinations showed some improved potency (red dots, $\mathrm{IC}_{50}$ $\mathrm{n}=3,1.7 \%$ and $\mathrm{IC}_{80}: \mathrm{n}=0,0 \%$ ) or decreased potency (blue dots, $\mathrm{IC}_{50}$ and $\left.\mathrm{IC}_{80}: \mathrm{n}=6,3.5 \%\right)$ for individual viruses these were relatively few and most showed less than $0.4 \log$ fold difference when compared to model predictions (Figures 4A, B).

For the triple combinations, similar results were observed with $157 / 170$ of the $\mathrm{IC}_{50}$ and $154 / 170$ of the $\mathrm{IC}_{80}$ values showing less than a $\log (2.5)$ difference. The mean on triple combinations was also close to $0(\log$-fold $-0.4<\mathrm{CI}<0.4)$ for both $\mathrm{IC}_{50}$ and $\mathrm{IC}_{80}$. Similarly, only a few individual viral titers showed a potential loss of potency for the $\mathrm{IC}_{50}(\mathrm{n}=8,4.7 \%)$ and $\mathrm{IC}_{80}(\mathrm{n}=11,6.5 \%)$ or a potential gain of potency $\left(\mathrm{IC}_{50}\right.$ and $\left.\mathrm{IC}_{80}: \mathrm{n}=5,3 \%\right)$ for triple combinations compared to the model (Figures 4C, D). None of the outliers in dual or triple combinations could be linked to 
A

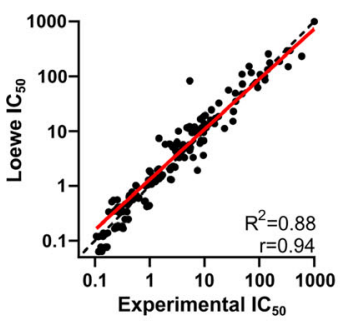

B

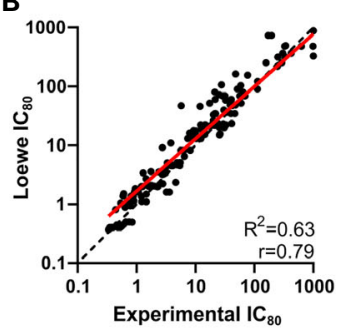

C

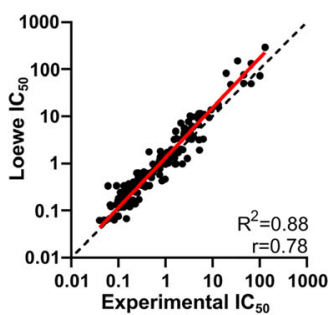

D

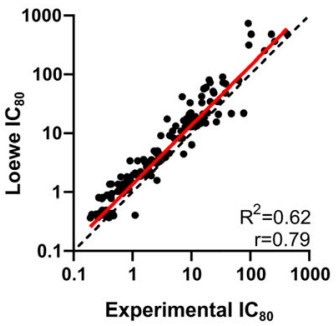

E
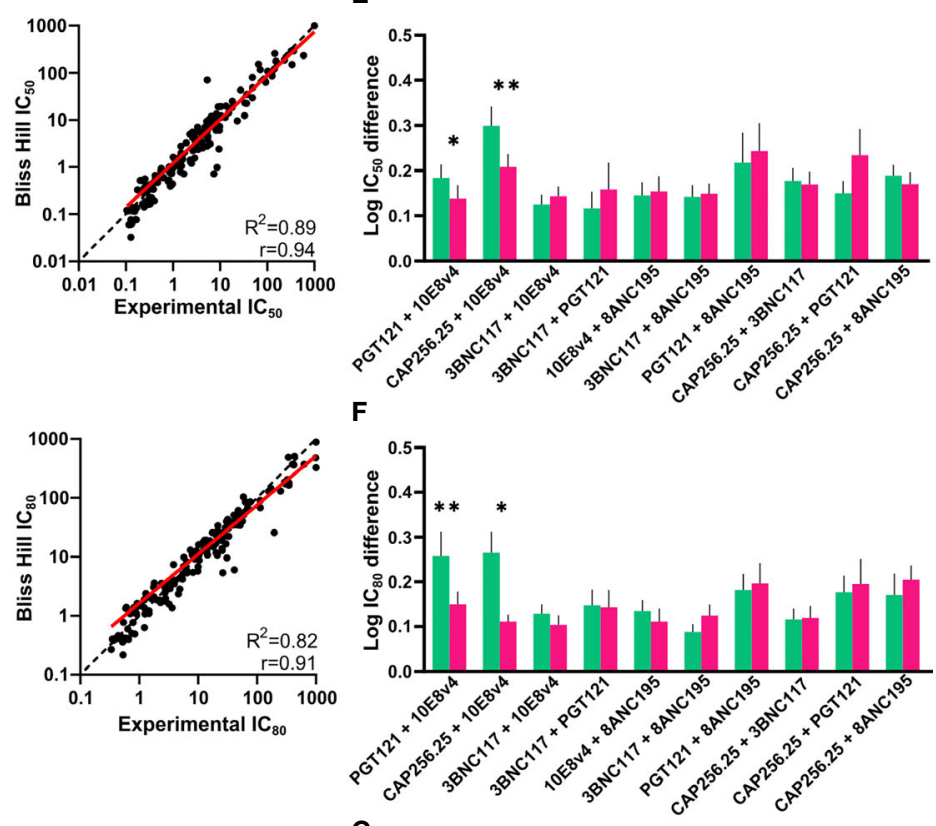

G
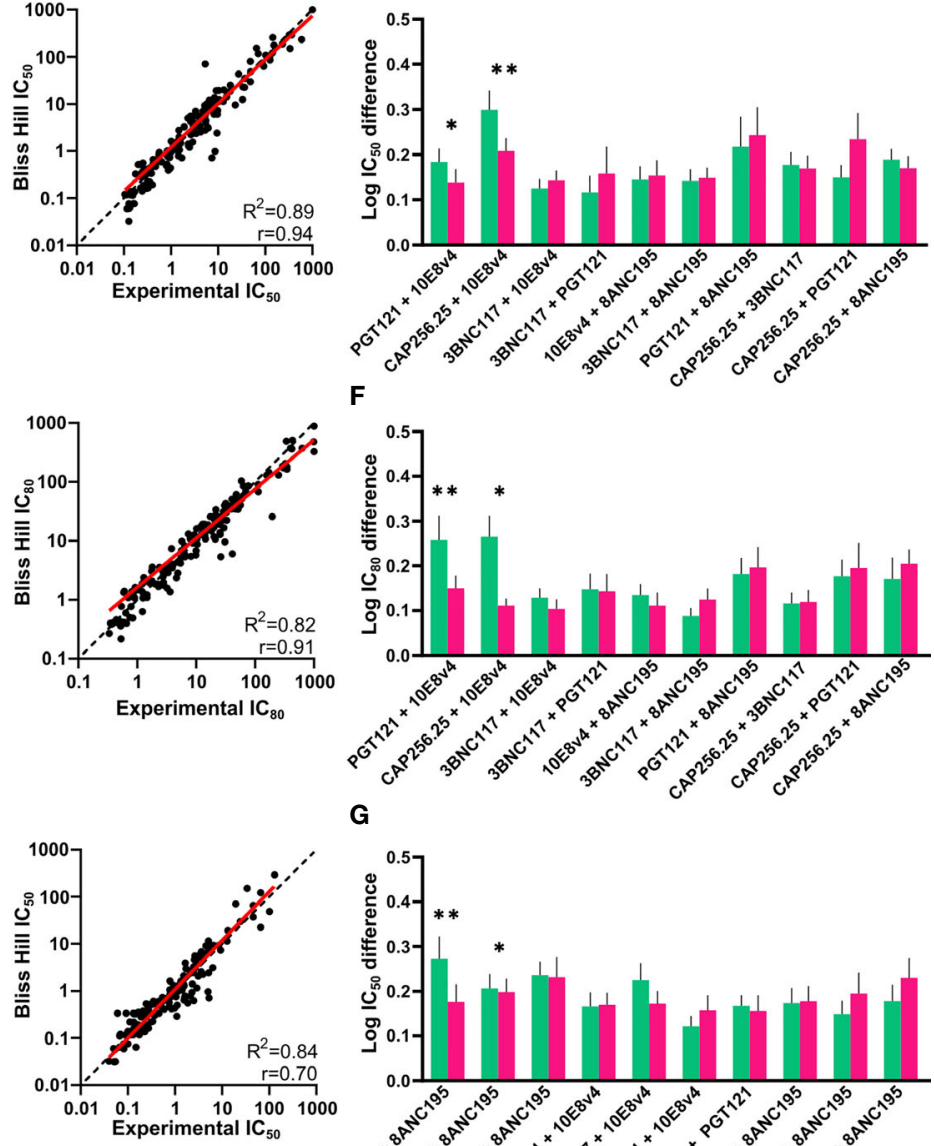

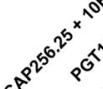

(1)

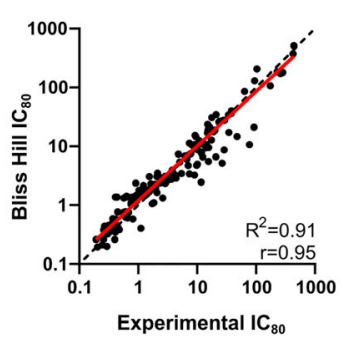

H
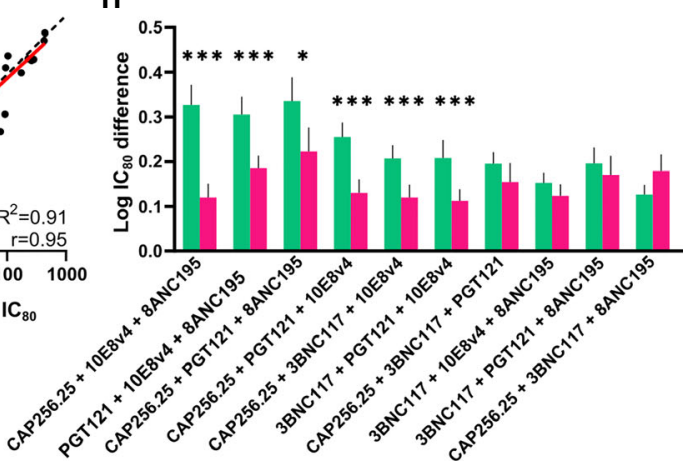

FIGURE 3 | Comparison of experimental and predicted combinations of dual and triple scFv. (A, B) $I C_{50}$ and IC 80 titers of dual antibody combinations plotted against the predicted $I \mathrm{I}_{50}$ and $I \mathrm{I}_{80}$ titers according to the Loewe Additive (left) and Bliss-Hill Independence (right) models. (C, D) Predicted IC $\mathrm{C}_{50}$ and II $\mathrm{C}_{80}$ titers of triple combinations versus the experimental $I_{50}$ and $I C_{80}$ titers. Values where both or all titers of single $s c F v>30 \mu g / m L$ are excluded. (E, F) Comparison of the absolute $\log \left(\mathrm{IC}_{50}\right)$ and $\log \left(\mathrm{IC}_{80}\right)$ difference between the experimental titers and predicted titers according to the Loewe Additive (green) and Bliss-Hill independence (purple) for the dual combinations. $(\mathbf{G}, \mathbf{H})$ Comparison of the absolute $\log \left({ }\left(\mathrm{C}_{50}\right)\right.$ and $\log \left({ }\left(\mathrm{C}_{80}\right)\right.$ difference between the experimental titers and predicted titers according to the Loewe Additive (green) and Bliss-Hill independence (purple) models for the triple combinations. For (A, B, E, F), a nonlinear robust regression $\log -\log$ line (red) and an equity line (black dotted) as well as $r, R 2$, are shown and $p<0.0001$. For (C, D, G, H), mean values are given with a standard error of the mean. A paired, Wilcoxon t-test was performed on each pair with significant $p$ values above the graphs $\left(p<0.05={ }^{\star} p<0.01={ }^{* \star} p<0.001={ }^{\star \star \star}\right)$. 


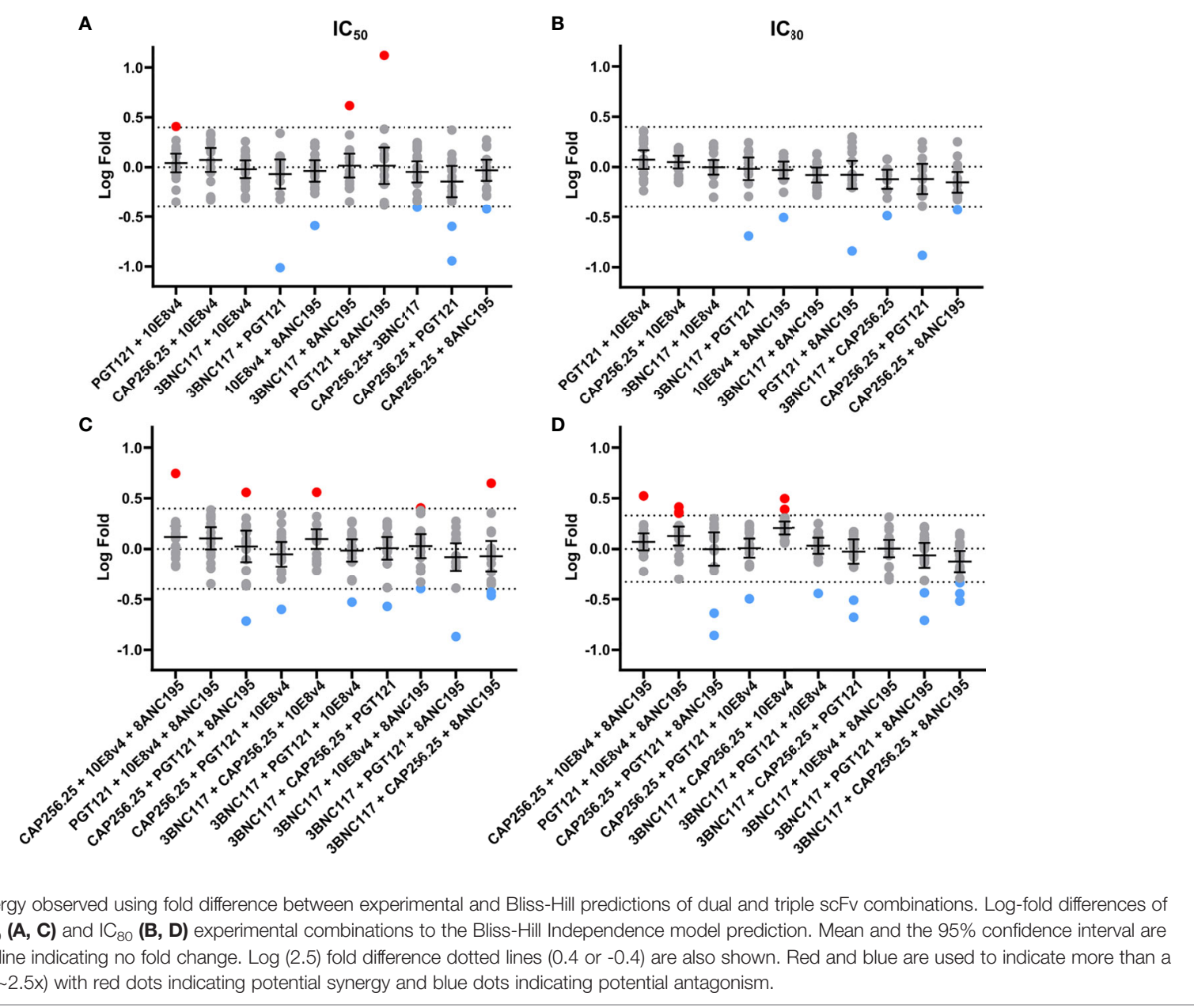

specific viral signatures (data not shown). Notwithstanding these few outliers, we, did not observe any significant synergy nor antagonism for dual or triple combinations of $s c F v$.

\section{Using the Bliss-Hill Model to Predict $\mathrm{IC}_{50}$ and $\mathrm{IC}_{80}$ Titers of scFv Combinations Against a Larger HIV Panel}

In order to assess their breadth-potency on a larger virus panel, we used the $\mathrm{IC}_{50}$ and $\mathrm{IC}_{80}$ data of single $\mathrm{scFv}$ to predict neutralization titers for combinations of two and three $s c F v$, now including 8ANC195, on a 45-virus panel described in our previous study (38) (see Supplementary Figure 1 for single $\mathrm{IC}_{50}$ in $\mathrm{nM}(\mathbf{A})$ and $\mathrm{IC}_{80}$ in $\mathrm{nM}(\mathbf{B})$ or $\mu \mathrm{g} / \mathrm{mL}$ (C, D) titers) (38). These theoretical scFv combinations were ranked based on their geometric mean potency using both $\mathrm{IC}_{50}$ and $\mathrm{IC}_{80}$ data for dual and triple combinations (Figures 5A, B, E, F). Combinations with the expected highest breadth and potency were plotted using breadth-potency curves (Figures 5C, D, G, H).

The best dual combinations, namely PGT121+10E8v4 (red), 3BNC117+10E8v4 (pink), and CAP256.25+10E8v4 (orange) were able to neutralize most viruses barring one at $\mathrm{IC}_{50}$ and $\mathrm{IC}_{80}$ (Figures 5A, B). The breadth-potency curves of the three
10E8v4-containing combinations reached $100 \%$ neutralization at the $\mathrm{IC}_{50}$ and $98 \%$ neutralization at the $\mathrm{IC}_{80}$ (colored breadthpotency plots versus grey, Figures 5 C, D) with most viruses neutralized between 0.1 and $1 \mu \mathrm{g} / \mathrm{mL}$ at $\mathrm{IC}_{80}$. The fourth combination of 10E8v4 with 8ANC195 was less effective due to the low potency of both antibodies and the limited breadth of 8ANC195, [see Supplementary Figure 3 (38)]. The other dual combinations showed reduced breadth (up to $30 \%$ at $50 \mu \mathrm{g} / \mathrm{mL}$ ) or reduced potency especially at $\mathrm{IC}_{80}$ (grey dots and lines). Some combinations such as PGT121+3BNC117 had a potent geometric mean below $0.1 \mu \mathrm{g} / \mathrm{mL}$ at $\mathrm{IC}_{50}$, but there was a larger spread of neutralization titers and so breadth was lost at $\mathrm{IC}_{80}$ (Figures $5 \mathrm{~A}, \mathbf{B}$ ). (See Supplementary Figure 4 for $\mathrm{IC}_{50}$ in $\mathrm{nM}(\mathbf{A})$ and $\mu \mathrm{g} / \mathrm{mL}$ (B) and $\mathrm{IC}_{80}$ in $\mathrm{nM}(\mathbf{C})$ and $\mu \mathrm{g} / \mathrm{mL}$ (D) titers of dual, and triple combinations predicted by the Bliss-Hill Independence model).

The triple combinations showed higher levels of potency and complete neutralization with $8 / 10$ combinations showing complete neutralization of the viral panel at $\mathrm{IC}_{50}$, and $6 / 10$ showing nearcomplete neutralization at $\mathrm{IC}_{80}$ (Figures 5E-H). Moreover, 7/10 triple combinations had a geometric mean potency below $0.1 \mu \mathrm{g} / \mathrm{mL}$ at $\mathrm{IC}_{50}$ (Figure 5E, green, dark green, and blue). Of these, three combinations all had a geometric mean $\mathrm{IC}_{80}$ below $1 \mu \mathrm{g} / \mathrm{mL}$ and neutralized up to 
A
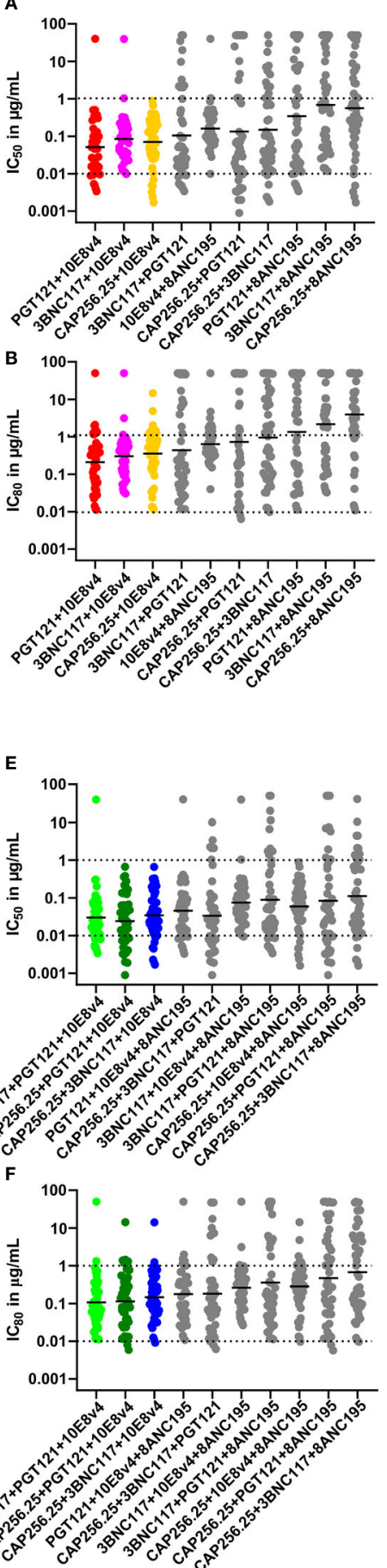

C
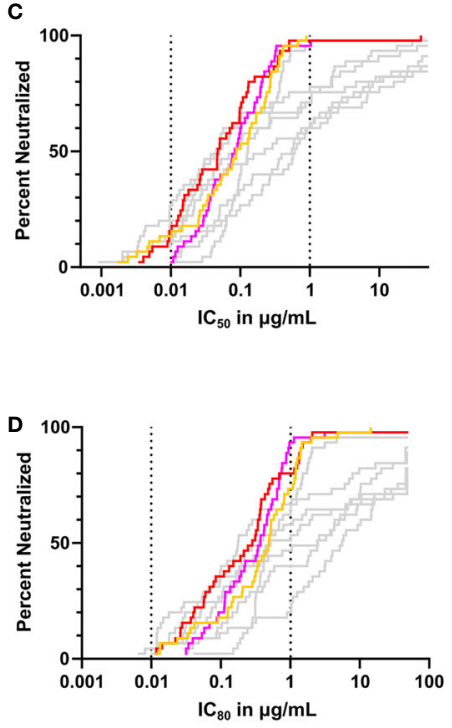

- PGT121+10E8v4

- 3BNC117+10E8v4

- CAP256.25+10E8v4

_ other combinations

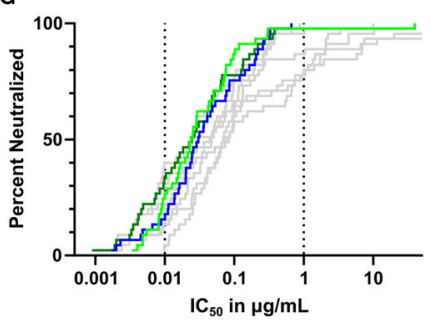

H

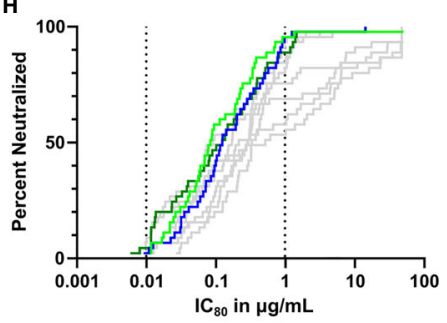

- 3BNC117+PGT121+10E8v4

- CAP256.25+PGT121+10E8v4

- CAP256.25+3BNC117+10E8v4

- other combinations

FIGURE 5 | Predicted breadth and potency of scFv combinations against large virus panel. (A) Scatter plot showing predicted IC $\mathrm{C}_{50}$ titers of dual combinations based on single scFv data for a panel of 45 viruses using the Bliss-Hill Independence model. The $\mathrm{IC}_{50}$ data is plotted in $\mu \mathrm{g} / \mathrm{mL}$ recalculated from $\mathrm{nM}$ based on the formula given in the methods section. (B) Predicted $\mathrm{IC}_{80}$ titers of dual combinations based on the Bliss-Hill Independence model ranked by geometric mean. (C) Breadth-potency curves of $\mathrm{IC}_{50}$ titers of most potent and broad dual combinations were plotted for the $\mathrm{IC}_{50}$. with the others in grey. (D) Breadth-potency curves from $I_{80}$ data for the most potent and broad dual combinations. (E) $I_{50}$ titers for triple combinations based on the Bliss-Hill Independence model. (F) Predicted $\mathrm{IC}_{80}$ titers for the triple combinations ranked based on geometric mean. (G) Breadth potency curves for the $\mathrm{IC}_{50}$ of the most potent and broad triple combinations are plotted. $\mathbf{( H )}$ The breadth-potency curves are based on $I_{C_{80}}$ titers of the most potent and broad combinations. The maximum neutralization for the $I C_{50}$ and $I C_{80}$ data is set at $50 \mu \mathrm{g} / \mathrm{mL}$ for all plots. Geometric mean is indicated by a black line in $\mathbf{A}, \mathbf{C}, \mathbf{E}$, and $\mathbf{G}$ Dotted lines are shown at $0.01 \mu \mathrm{g} / \mathrm{mL}$ and $1 \mu \mathrm{g} / \mathrm{mL}$ for breadthpotency plots $\mathrm{IC}_{50}$ and the $\mathrm{IC}_{80}(\mathbf{B}, \mathbf{D}, \mathbf{F}, \mathbf{H})$. Each ScFv is present in the combination at the titer indicated. 
$96 \%$ of viruses (Figures $\mathbf{5 F}, \mathbf{H}$ ). This indicated that triple combinations are able to reach nearly $100 \%$ neutralization at lower concentrations for both $\mathrm{IC}_{50}$ and $\mathrm{IC}_{80}$ (see Supplementary Figure 4 for $\mathrm{IC}_{50}$ in $\mathrm{nM}(\mathbf{A})$ and $\mu \mathrm{g} / \mathrm{mL}$ (B) and $\mathrm{IC}_{80}$ in $\mathrm{nM}$ (C) and $\mu \mathrm{g} / \mathrm{mL}$ (D) titers of dual, and triple combinations predicted by the Bliss-Hill Independence model).

The predicted breadth of each combination was next determined at four concentrations: $0.1,1,10$, and $50 \mu \mathrm{g} / \mathrm{mL}$ in addition to the geometric mean for the combinations tested (with a cutoff at $50 \mu \mathrm{g} / \mathrm{mL}$ ). Combining these $\mathrm{scFv}$ improved the coverage at all concentrations for both $\mathrm{IC}_{50}$ and $\mathrm{IC}_{80}$ (Figure 6). Breadth for dual combinations ranged from $84 \%$ to $100 \%$ at $\mathrm{IC}_{50}<50 \mu \mathrm{g} / \mathrm{ml}$ and $80 \%$ to $100 \%$ at $\mathrm{IC}_{80}<50 \mu \mathrm{g} / \mathrm{ml}$. For dual combinations, $100 \%$ breadth was reached for one combination at $\mathrm{IC}_{50}<1 \mu \mathrm{g} / \mathrm{mL}$, and for four combinations at $\mathrm{IC}_{50}<50 \mu \mathrm{g} / \mathrm{mL}$. For the $\mathrm{IC}_{80}, 98 \%$ breadth was obtained at $10 \mu \mathrm{g} / \mathrm{mL}$ for the same combinations. Most combinations of three scFv had $100 \%$ breadth at $\mathrm{IC}_{50}<50 \mu \mathrm{g} / \mathrm{ml}$, except for PGT121+3BNC117+8ANC195 and CAP256.25+PGT121 +8 ANC195, which had a breadth of $96 \%$ and $93 \%$ respectively. Breadth was especially improved for lower concentrations at $\mathrm{IC}_{80}$. For example, breadth for single scFv ranged from 0 to $44 \%$ for $\mathrm{IC}_{50}<0.1 \mu \mathrm{g} / \mathrm{ml}$ and 0 to $24 \%$ for $\mathrm{IC}_{80}<0.1 \mu \mathrm{g} / \mathrm{ml}$, whereas dual combinations ranged from 22 to $62 \%$ for $\mathrm{IC}_{50}$ and 2 to $29 \%$ for $\mathrm{IC}_{80}$. At the same cutoff, the breadth for combinations of 3 antibodies ranged from $47 \%$ to $82 \%$ for $\mathrm{IC}_{50}$ and 16 to $40 \%$ for $\mathrm{IC}_{80}$. Geometric mean potency for the panel also improved from $0.2-4.95 \mu \mathrm{g} / \mathrm{mL}$ for single $\mathrm{scFv}$ to $0.27-2.08 \mu \mathrm{g} / \mathrm{mL}$ for dual combinations and $0.09-0.61 \mu \mathrm{g} / \mathrm{mL}$ for triple combinations at $\mathrm{IC}_{80}$. This was expected as the titers were calculated as containing the same amount of each $\mathrm{scFv}$ at that concentration.

Since PGT121, 3BNC117, and CAP256.25 all had good potencies as $\mathrm{scFv}$, using these together with $10 \mathrm{E} 8 \mathrm{v} 4$ resulted in improved potency of the combination. Moreover, scFv such as CAP256.25 and PGT121 and/or 3BNC117 have complementary profiles, with $3 \mathrm{BNC} 117$, for example, being especially potent against subtype B viruses and CAP256.25 being potent against subtype $C$ viruses (see Supplementary Data 1 for the $\mathrm{IC}_{50}$ and $\mathrm{IC}_{80}$ of single $\mathrm{scFv}$ ) (38). $10 \mathrm{E} 8 \mathrm{v} 4$ is the broadest $\mathrm{scFv}$ and that resulted in the combinations containing 10E8v4 having the highest breadth. As a result, four of the five triple combinations with the best geometric mean titers included $10 \mathrm{E} 8 \mathrm{v} 4$. Conversely, introducing less potent or less broad antibodies such as 8ANC195 resulted in less favorable antibody combinations, where 5 out of 6 combinations with the lowest potency and breadth contained 8ANC195, consistent with the relatively lower potency and breadth of this antibody. Of the top five, three combinations, CAP256.25+PGT121+10E8v4

\begin{tabular}{|c|c|c|c|c|c|c|c|c|c|c|}
\hline & \multicolumn{5}{|c|}{$\mathrm{IC}_{50}$ in $\mu \mathrm{g} / \mathrm{mL}$} & \multicolumn{5}{|c|}{$\mathrm{IC}_{80}$ in $\mu \mathrm{g} / \mathrm{mL}$} \\
\hline & 0.1 & 1 & 10 & 50 & geomean & 0.1 & 1 & 10 & 50 & geomean \\
\hline CAP256.25 & $20 \%$ & $47 \%$ & $62 \%$ & $62 \%$ & 0.20 & $11 \%$ & $16 \%$ & $29 \%$ & $49 \%$ & 1.82 \\
\hline PGT121 & $44 \%$ & $56 \%$ & $62 \%$ & $71 \%$ & 0.12 & $24 \%$ & $44 \%$ & $51 \%$ & $56 \%$ & 0.20 \\
\hline 3BNC117 & $29 \%$ & $47 \%$ & $69 \%$ & $78 \%$ & 0.39 & $13 \%$ & $31 \%$ & $62 \%$ & $69 \%$ & 0.98 \\
\hline 10E8v4 & $27 \%$ & $96 \%$ & $98 \%$ & $100 \%$ & 0.21 & $2 \%$ & $49 \%$ & $98 \%$ & $98 \%$ & 0.82 \\
\hline 8ANC195 & $0 \%$ & $20 \%$ & $51 \%$ & $69 \%$ & 2.94 & $0 \%$ & $7 \%$ & $24 \%$ & $40 \%$ & 4.95 \\
\hline CAP256.25+10E8v4 & $53 \%$ & $100 \%$ & $100 \%$ & $100 \%$ & 0.07 & $18 \%$ & $73 \%$ & $98 \%$ & $100 \%$ & 0.36 \\
\hline PGT121+10E8v4 & $69 \%$ & $98 \%$ & $98 \%$ & $100 \%$ & 0.05 & $36 \%$ & $80 \%$ & $98 \%$ & $98 \%$ & 0.19 \\
\hline 3BNC117+10E8v4 & $60 \%$ & $96 \%$ & $98 \%$ & $100 \%$ & 0.08 & $20 \%$ & $93 \%$ & $98 \%$ & $98 \%$ & 0.27 \\
\hline 10E8v4+8ANC195 & $40 \%$ & $96 \%$ & $98 \%$ & $100 \%$ & 0.16 & $2 \%$ & $64 \%$ & $98 \%$ & $98 \%$ & 0.57 \\
\hline PGT121+3BNC117 & $64 \%$ & $78 \%$ & $91 \%$ & $96 \%$ & 0.08 & $38 \%$ & $67 \%$ & $82 \%$ & $91 \%$ & 0.28 \\
\hline CAP256.25+3BNC117 & $51 \%$ & $71 \%$ & $93 \%$ & $98 \%$ & 0.13 & $27 \%$ & $51 \%$ & $71 \%$ & $89 \%$ & 0.58 \\
\hline CAP256.25+8ANC195 & $27 \%$ & $60 \%$ & $82 \%$ & $91 \%$ & 0.36 & $11 \%$ & $20 \%$ & $58 \%$ & $80 \%$ & 2.08 \\
\hline PGT121+8ANC195 & $44 \%$ & $60 \%$ & $80 \%$ & $87 \%$ & 0.16 & $24 \%$ & $47 \%$ & $67 \%$ & $82 \%$ & 0.62 \\
\hline 3BNC117+8ANC195 & $33 \%$ & $60 \%$ & $78 \%$ & $87 \%$ & 0.36 & $13 \%$ & $40 \%$ & $67 \%$ & $80 \%$ & 1.00 \\
\hline CAP256.25+PGT121 & $64 \%$ & $71 \%$ & $80 \%$ & $84 \%$ & 0.04 & $36 \%$ & $58 \%$ & $69 \%$ & $82 \%$ & 0.29 \\
\hline CAP256.25+3BNC117+10E8v4 & $76 \%$ & $100 \%$ & $100 \%$ & $100 \%$ & 0.03 & $42 \%$ & $96 \%$ & $98 \%$ & $100 \%$ & 0.15 \\
\hline CAP256.25+PGT121+10E8v4 & $78 \%$ & $100 \%$ & $100 \%$ & $100 \%$ & 0.02 & $47 \%$ & $89 \%$ & $98 \%$ & $100 \%$ & 0.11 \\
\hline CAP256.25+10E8v4+8ANC195 & $60 \%$ & $100 \%$ & $100 \%$ & $100 \%$ & 0.06 & $20 \%$ & $82 \%$ & $98 \%$ & $100 \%$ & 0.28 \\
\hline PGT121+3BNC117+10E8v4 & $87 \%$ & $98 \%$ & $98 \%$ & $100 \%$ & 0.03 & $58 \%$ & $96 \%$ & $98 \%$ & $98 \%$ & 0.09 \\
\hline PGT121+10E8v4+8ANC195 & $76 \%$ & $98 \%$ & $98 \%$ & $100 \%$ & 0.05 & $42 \%$ & $84 \%$ & $98 \%$ & $98 \%$ & 0.16 \\
\hline 3BNC117+10E8v4+8ANC195 & $62 \%$ & $96 \%$ & $98 \%$ & $100 \%$ & 0.07 & $22 \%$ & $93 \%$ & $98 \%$ & $98 \%$ & 0.23 \\
\hline CAP256.25+PGT121+3BNC117 & $78 \%$ & $87 \%$ & $100 \%$ & $100 \%$ & 0.03 & $53 \%$ & $76 \%$ & $89 \%$ & $100 \%$ & 0.18 \\
\hline CAP256.25+3BNC117+8ANC195 & $58 \%$ & $78 \%$ & $96 \%$ & $100 \%$ & 0.11 & $29 \%$ & $53 \%$ & $82 \%$ & $98 \%$ & 0.61 \\
\hline PGT121+3BNC117+8ANC195 & $67 \%$ & $80 \%$ & $91 \%$ & $96 \%$ & 0.07 & $40 \%$ & $69 \%$ & $84 \%$ & $93 \%$ & 0.25 \\
\hline CAP256.25+PGT121+8ANC195 & $64 \%$ & $78 \%$ & $93 \%$ & $93 \%$ & 0.05 & $38 \%$ & $58 \%$ & $80 \%$ & $93 \%$ & 0.34 \\
\hline
\end{tabular}

FIGURE 6 | Neutralization breadth for single and combinations of scFv against a 45-virus panel at four concentrations. Percentage neutralization at 0.1, 1, 10, and $50 \mu \mathrm{g} / \mathrm{mL}$ was calculated from single scFv titers and from predicted scFv dual and triple combination titers for the $\mathrm{IC}_{50}$ and $\mathrm{IC}_{80}$. Colors indicate percentage neutralization with $1-19 \%$ in green, $20-49 \%$ yellow, $50-79 \%$ yellow-orange, $80-89 \%$ orange, $90-99 \%$ red and $100 \%$ dark red. Geometric mean at $50 \mu \mathrm{g} / \mathrm{mL}$ is also given. Each scFv is present in the combinations at the titers indicated. 
and CAP256.25+3BNC117+10E8v4 and CAP256.25+8ANC195 $+10 \mathrm{E} 8 \mathrm{v} 4$ neutralized all viruses below $1 \mu \mathrm{g} / \mathrm{mL}$ and $98 \%$ of viruses at $\mathrm{IC}_{80}$ below $10 \mu \mathrm{g} / \mathrm{mL}$. The best ranked PGT121 $+3 \mathrm{BNC} 117+10 \mathrm{E} 8 \mathrm{v} 4$ combination neutralized $96 \%$ of viruses below $1 \mu \mathrm{g} / \mathrm{mL}$ and $98 \%$ of viruses below $10 \mu \mathrm{g} / \mathrm{mL}$ at the $\mathrm{IC}_{80}$ value. This analysis indicated a significant gain of potency and neutralization breadth at lower concentrations than single $\mathrm{scFv}$ at both $\mathrm{IC}_{50}$ and $\mathrm{IC}_{80}$. This indicated that combinations of scFv were able to increase the coverage at lower concentrations, which will be vital in clinical settings.

\section{Predicting the Efficacy of ScFv Combinations}

The AMP trial showed that viral isolates that were sensitive to VRC01 with an $\mathrm{IC}_{80}<1 \mu \mathrm{g} / \mathrm{mL}$ were prevented from establishing infection in $75 \%$ of cases. As indicated in Figures 5 and $\mathbf{6}, \mathrm{scFv}$ combinations can reach significant coverage by a single antibody at this potency with the best $\mathrm{scFv}$ combination potentially reaching a $96 \%$ protection level. However, other antibody classes may need higher levels of potency to provide similar protection as VRC01 and viral isolates which are neutralized close to this cut-off may allow for breakthrough. Dual coverage will be able to overcome these issues by neutralizing breakthrough viruses at higher potencies and providing a backup in case antibody levels drop. Therefore, using this cut-off, we calculated the predicted dual coverage (i.e. by at least two scFv) of the combinations using the thresholds of single $\mathrm{scFv} \mathrm{IC}_{80}<1 \mu \mathrm{g} /$ $\mathrm{ml}$ and $<10 \mu \mathrm{g} / \mathrm{mL}$. We found for dual combinations, the dual active coverage at $1 \mu \mathrm{g} / \mathrm{mL}$ ranged from $20 \%$ with improvement at $10 \mu \mathrm{g} / \mathrm{mL}$ to $51 \%$ for PGT121+10E8v4 (Figures 7A, B), This ranged from $0-20 \%$ at $1 \mu \mathrm{g} / \mathrm{mL}$ and $9-62 \%$ for other combinations of two antibodies (See Supplementary Figure 5).

This was somewhat improved for triple combinations where we observed up to $58-80 \%$ dual active coverage at an $\mathrm{IC}_{80}$ of
A

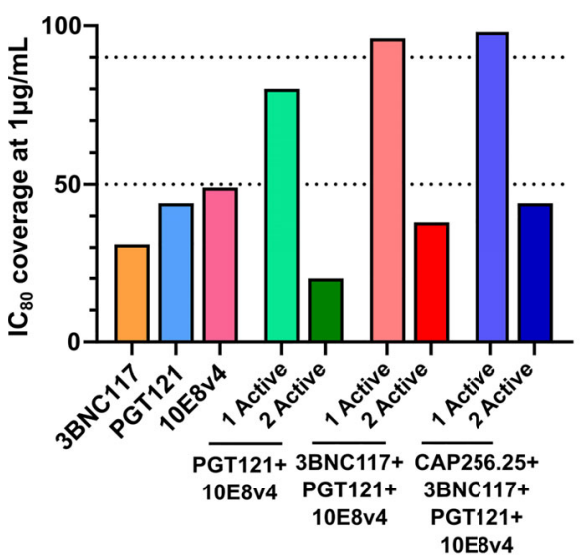

C

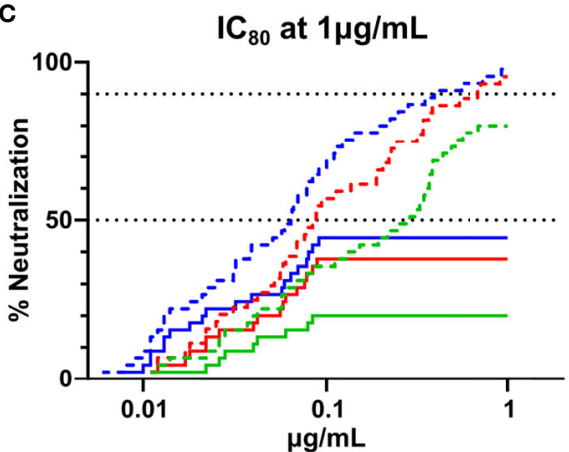

- PGT121+10E8v4

- 3BNC117+PGT121+10E8v4

- CAP256.25+3BNC117+PGT121+10E8v4
B

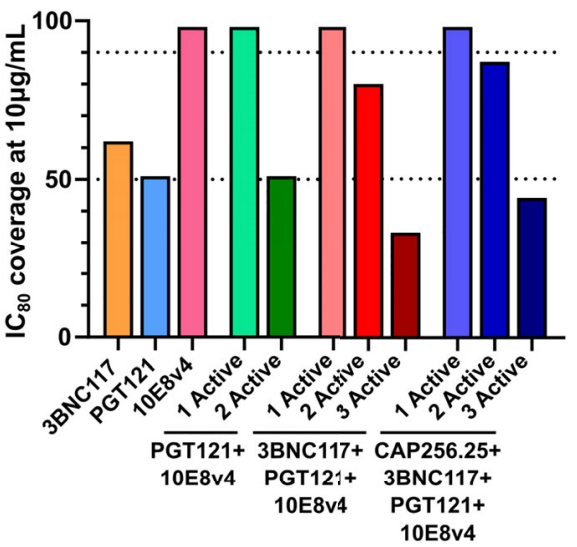

D $\mathrm{IC}_{80}$ at $10 \mu \mathrm{g} / \mathrm{mL}$

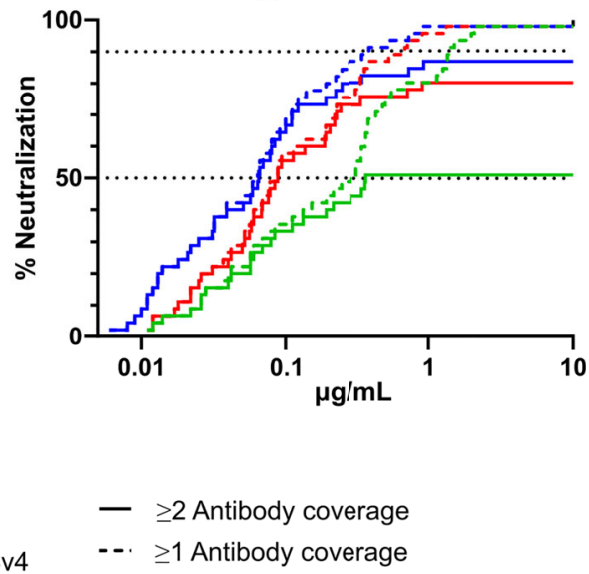

FIGURE 7 | Predicted coverage and estimated efficacy of best scFv combinations. (A, B) Active coverage by one, two, three or four scFv was calculated at 2 concentrations $\left(1 \mu \mathrm{g} / \mathrm{mL}(\mathbf{A})\right.$ and $10 \mu \mathrm{g} / \mathrm{mL}$ (B) at $\mathrm{IC}_{80}$ based on the predicted titers according to the Bliss-Hill Independence model. The broadest triple and quadruple combinations are shown. (C, D) Breadth Potency curves of active coverage of 1 and 2 scFv are given for the best combinations (3BNC17+10E8v4 and 3BNC17+10E8v4+PGT121, and CAP256.25+3BNC17+10E8v4+PGT121) at $1 \mu \mathrm{g} / \mathrm{mL}$ (C) and 10 $\mu \mathrm{g} / \mathrm{mL}$ (D). 50\% and 90\% breadth are indicated by the dotted lines in $(\mathbf{C}, \mathbf{D})$. 
$10 \mu \mathrm{g} / \mathrm{mL}$. The best 3-combinations,3BNC117+PGT121+10E8v4 showing the highest active coverage at $10 \mu \mathrm{g} / \mathrm{mL}$ of $80 \%$. Generally, triple combinations showed higher levels of active coverage by 2 antibodies and often included both 10E8v4 and 3BNC117. Similar to the dual combinations, low dual coverage was observed at $1 \mu \mathrm{g} / \mathrm{mL}$ up to $38 \%$ (See Figure $7 \mathbf{A}$, Supplementary Figure 5. This could not be significantly improved for quadruple combinations which showed $44 \%$ and $87 \%$ dual coverage respectively at 1 and $10 \mu \mathrm{g} / \mathrm{mL}$. This loss of active coverage by multiple antibodies is also demonstrated in the breadth potency curves (Figures 7C, D). These curves clearly show that although at $10 \mu \mathrm{g} / \mathrm{mL}$ most of the dual coverage is maintained there is a significant drop off at $1 \mu \mathrm{g} / \mathrm{mL}$. This was mainly due to antibodies such as 3BNC117, PGT121, and 10E8v4 showing only $31-49 \%$ breadth at $1 \mu \mathrm{g} / \mathrm{mL}$ and the CAP256.25 scFv losing significant potency compared to the IgG (38). IgG combinations including this antibody could show slightly better active coverage by 2 antibodies, up to $53 \%$ at an $\mathrm{IC}_{80}$ of $1 \mu \mathrm{g} / \mathrm{mL}$ and up to $91 \%$ at $10 \mu \mathrm{g} / \mathrm{mL}$ (Supplementary Data 6A for predictions of IgG combinations titers in $\mu \mathrm{g} / \mathrm{mL}$ and $\mathbf{6 B}$ for neutralization breadth at 4 concentrations and dual coverage by IgG) (38). The other IgG and scFv showed similar levels of potency with specifically the $10 \mathrm{E} 8 \mathrm{v} 4 \mathrm{scFv}$ retaining all of its potency explaining why the IgG combinations did not show higher levels of dual active coverage at $1 \mu \mathrm{g} / \mathrm{mL}$ (Figure 7 , Supplementary Figure 6B). This indicated that potency of single IgG and $s c F v$ needs to be improved to obtain higher levels of active coverage by 2 antibodies at lower antibody levels. The combination data demonstrate that the benefits of combinations of IgG targeting different HIV epitopes apply also to the smaller and more versatile scFv fragments.

\section{DISCUSSION}

Combinations of $\mathrm{scFv}$ antibodies were able to enhance the breadth and potency of HIV-1 neutralization compared to a single scFv. Specifically, several triple combinations reached $100 \%$ coverage at $\mathrm{IC}_{50}$ and $\mathrm{IC}_{80}$ due to complementary neutralization profiles. Dual and triple combinations of $\mathrm{scFv}$ demonstrated broad coverage in the potency range that correlated with prevention in the AMP trials $\left(\mathrm{IC}_{80}<1 \mu \mathrm{g} / \mathrm{mL}\right)$ and would therefore be expected to be highly effective in combating HIV transmission in high incidence areas.

Generally, dual scFv combinations followed an independent action model rather than a synergistic model of potency. The potency of the combination was usually similar to the potency of the most potent $\mathrm{scFv}$ in that mix. Although scFv may show less steric interference between antibodies this did not result in scFv showing significant potency improvements when used in combination. The close positioning of certain epitopes may prevent dual binding such as between V3 and CD4bs targeting $s c F v$ indicating that steric hindrance may have still impacted the scFv. Given the distinct MPER epitope located on the gp41 subunit instead of the gp120 subunit, we also expected independent effects for antibodies combined with 10E8v4, which was somewhat indicated in comparing experimental results with the most potent scFv. However, besides a few outliers, this was not apparent using the Bliss-Hill model. It is likely that binding of the MPER antibody confers conformational changes upon binding to its epitope precluding neutralization by other antibodies (47-50). scFv may be especially advantageous in bispecific constructs as their smaller size allows for easier expression. Bispecific products will also increase the local concentration of the second antibody and with the appropriate linker may in such cases allow for synergy. Similarly, minor losses of potency compared to the most potent scFv were overall a rare occurrence and were negated with the addition of a third antibody (in a triple combination with e.g. 10E8v4). The few cases of antagonism noted for scFv combinations may also be due to conformational changes rather than steric hindrance, which would occur after antibody binding. To explore these aspects, scFv-trimer complex crystallization studies would have to be done.

The Loewe model tended to underestimate the potency at $\mathrm{IC}_{80}$ particularly of triple combinations. It also often predicted low-level synergy for combinations containing the MPER antibody 10E8v4 and the V2 antibody CAP256.25. The Bliss-Hill model did not indicate significant antagonism and/or synergy for any combination at either $\mathrm{IC}_{50}$ or $\mathrm{IC}_{80}$. We did observe a few individual outliers where for example the combination showed some improvement in $\mathrm{IC}_{50}$ and $\mathrm{IC}_{80}$ (CAP256.25+3BNC117+10E8v4) or similarly (3BNC117 + PGT121) showed loss of potency against individual viruses but no specific viral signature could be identified. Some of these may be limitations of the model itself as these tended to occur more often with viruses where the neutralization curves were not sigmoidal or with a low slope (18). The Bliss-Hill model tended to be better at predicting the $\mathrm{IC}_{80}$ titers and both models were matched for the $\mathrm{IC}_{50}$ titers. This finding is similar to IgG combinations where the Bliss-Hill model was also more accurate at predicting combination titers compared to the Loewe model, therefore the Bliss-Hill model was the preferred model for analyses of larger scFv datasets.

From a clinical perspective, the use of antibody combinations may mitigate the impact of suboptimal antibody levels. Overlapping neutralization can enhance coverage against single viruses, which ensures that complete viral neutralization is achieved at lower concentrations of antibody. The selection of antibody combinations with high potency $\left(\mathrm{IC}_{80}\right)$ can more effectively counter declining antibody levels associated with passive administration. Although combinations of two $s c F v$ neutralized $100 \%$ of viruses at the highest concentration tested, the coverage was much reduced at lower concentrations, whereas triple antibody combinations demonstrated much higher coverage at lower concentrations by combining broad antibodies with very potent antibodies. For example, at an $\mathrm{IC}_{50}$ of $1 \mu \mathrm{g} / \mathrm{mL}, 100 \%$ of viruses were neutralized and at an $\mathrm{IC}_{80}$ of $1 \mu \mathrm{g} / \mathrm{mL}, 96 \%$ of viruses were neutralized. This demonstrates that complementary neutralization of the same virus is extremely advantageous, which was previously demonstrated for combinations of IgG (20). 
Besides improved coverage, we also observed improved active coverage by 2 antibodies for triple combinations compared to dual combinations (19). In experimental combinations, neutralization slopes were also improved by combinations of antibodies, especially $\mathrm{IC}_{80}$ titers and neutralization plateaus (less than $100 \%$ neutralization of a virus) were also less common with antibody combinations (data not shown) (18). It may also be beneficial to use antibodies or $\mathrm{scFv}$ that bind trimers in different states; for example, CAP256.25 binds early, whereas 10E8v4 likely binds trimers that are in an intermediate state allowing for complementarity in virus neutralization (51-53). Clinically, active coverage by multiple antibodies will prevent antibody escape when the serum titers drop to close to the neutralization range. The AMP trial demonstrated that if the VRC01 antibody levels dropped, protection against less sensitive viruses $\left(\mathrm{IC}_{80}>1 \mu \mathrm{g} / \mathrm{mL}\right)$ was lost (17). This may differ for other antibodies or for antibodies targeting different epitopes and combinations may also provide dual active coverage of the viral quasispecies further improving this level of protection (54, 55). This highlights the need to use more potent antibodies but also to improve individual antibody potency. In the future, bNAbs and $s c F v$ may also need to be assessed in PBMC neutralization assays which may more accurately resemble in vivo neutralization, and could more accurately predict potency $(17,55)$. We observed that although overall coverage was improved, active coverage by multiple antibodies was low for both IgG and scFv using this set of antibodies. There are multiple efforts ongoing to improve antibody potency and bioavailability. Titers are likely to improve if newer scFv are developed which retain better potency compared to the IgG. Moreover, the selection of antibodies with optimal potency to cover geographically relevant viruses will ensure efficacy in the region.

For long-term antibody-mediated protection, adherence, and maintaining sufficient plasma levels in a wider population is critically important. At lower concentrations, scFv and IgG lose coverage especially in the ability to fully neutralize the virus (concentrations below $\mathrm{IC}_{80}$ titers). This is also observed for IgG, indicating that all the antibodies in the combination must be kept at optimal levels. For IgG, one way to achieve this has been to introduce mutations in the Fc portion of the antibody to increase the half-life by up to 6 months $(56,57)$. A second option is to introduce them into the body via a stable expression system through a vectored immunoprophylaxis (VIP) approach. Some bNAbs were recently expressed using AAV, showing modest levels in vivo $(58,59)$. However, due to the space constraints on vectors, constructs with multi-specific modalities would prove difficult. Bispecific products, which would partially overcome this, are also limited by space constraints. scFv in comparison with their much smaller size may be more readily expressed on AAV, allowing for the expression of multiple scFv continuously. $\mathrm{scFv}$ have a genetic size approximately 2.6-times smaller than IgG allowing for the expression of minimally three scFv per AAV, and improved expression levels $(9,29,60-66)$. AAV based scFv expression can help overcome the short half-life of scFv due to their lack of an
Fc region. Some studies have shown success in the use of AAV based scFv for Alzheimer's disease, and Amyotrophic Lateral Sclerosis amongst others $(61,67,68)$. In vivo data will be required to determine the antigenicity and bioavailability of scFv. However, scFv conjugated to short amino acid peptides or linked to targeting molecules were shown to have significant increases in bioavailability and stability (69-72). These strategies mitigate some of the challenges facing scFv.

The scFv studied here demonstrated high breadth and potency when used in combination. Although only a limited number of $s c F v$ were tested on a small panel of viruses, we demonstrated their potential against a larger panel of viruses through modeling. By selecting bNAbs that target all five epitopes we also showed the potential for complementary effects. These scFv showed little to no antagonism. As more potent $\mathrm{scFv}$ are engineered combinations with even better efficacy may be found. In addition, as $s c F v$ are more readily expressed on vectors, this could in future provide, an alternative avenue for the use of bNAbs in passive immunization. The encouraging results of the AMP trials are expected to fast-track the need to consider long-term delivery approaches for those antibodies with clinical benefit.

\section{DATA AVAILABILITY STATEMENT}

The original contributions presented in the study are included in the article/Supplementary Material. Further inquiries can be directed to the corresponding author.

\section{ETHICS STATEMENT}

Ethics approval was obtained as per local regulations (M160341). Antibody sequences were obtained from publicly available databases.

\section{AUTHOR CONTRIBUTIONS}

RD performed all experiments, data interpretation, figures and manuscript generation, and literature review. KW performed data analysis and advised on statistical analysis. PM and LM supervised the project and assisted with data interpretation and manuscript writing. All authors contributed to the article and approved the submitted version.

\section{FUNDING}

We acknowledge research funding from the South African Medical Research Council (SAMRC) Flagship Project, the NIH through a U01 grant (U01AI116086), the Poliomyelitis Research Fund (PRF) through a PRF research grant (17/15), and the Centre for the AIDS 
Program of Research (CAPRISA). CAPRISA is funded by the South African HIV/AIDS Research and Innovation Platform of the South African Department of Science and Technology and was initially supported by the U.S. NIAID, NIH, U.S. Department of Health and Human Services grant U19 AI51794. R.T.V.D. is supported by a Poliomyelitis Research Foundation Ph.D. bursary (W 16/72). PM is supported by the South African Research Chairs Initiative of the Department of Science and Innovation and National Research Foundation of South Africa (grant no. 98341). KW is supported by the Bill and Melinda Gates Foundation Collaboration for AIDS Vaccine Discovery grant OPP1032144 (Comprehensive Antibody Vaccine Immune Monitoring Consortium CAVIMC) (https:// www.cavd.org/Pages/default.aspx). The funders had no role in study design, data collection, and analysis, decision to publish, or preparation of the manuscript.

\section{REFERENCES}

1. Julg B, Liu P-T, Wagh K, Fischer WM, Abbink P, Mercado NB, et al. Protection Against a Mixed SHIV Challenge by a Broadly Neutralizing Antibody Cocktail. Sci Transl Med (2017) 9:eaao4235. doi: 10.1126/ scitranslmed.aao4235

2. Saunders KO, Wang L, Joyce MG, Yang Z-YY, Balazs AB, Cheng C, et al. Broadly Neutralizing Human Immunodeficiency Virus Type 1 Antibody Gene Transfer Protects Nonhuman Primates From Mucosal SimianHuman Immunodeficiency Virus Infection. J Virol (2015) 89:8334-45. doi: 10.1128/jvi.00908-15

3. Martinez-Navio JM, Fuchs SP, Pantry SN, Lauer WA, Duggan NN, Keele BF, et al. Adeno-Associated Virus Delivery of Anti-HIV Monoclonal Antibodies Can Drive Long-Term Virologic Suppression. Immunity (2019) 50:567575.e5. doi: 10.1016/j.immuni.2019.02.005

4. Parren PW, Marx PA, Hessell AJ, Luckay A, Harouse J, Cheng-Mayer C, et al. Antibody Protects Macaques Against Vaginal Challenge With a Pathogenic R5 Simian/Human Immunodeficiency Virus at Serum Levels Giving Complete Neutralization In Vitro. J Virol (2001) 75:8340-7. doi: 10.1128/ JVI.75.17.8340-8347.2001

5. Klein F, Mouquet H, Dosenovic P, Scheid JF, Scharf L, Nussenzweig MC. Antibodies in HIV-1 Vaccine Development and Therapy. Science (80-) (2013) 341:1199-204. doi: 10.1126/science.1241144

6. Bekker L-G, Moodie Z, Grunenberg N, Laher F, Tomaras GD, Cohen KW, et al. Subtype C ALVAC-HIV and Bivalent Subtype C Gp120/MF59 HIV-1 Vaccine in Low-Risk, HIV-Uninfected, South African Adults: A Phase 1/2 Trial. Lancet HIV (2018) 5:e366-78. doi: 10.1016/S2352-3018(18)30071-7

7. Karasavvas N, Billings E, Rao M, Williams C, Zolla-Pazner S, Bailer RT, et al. The Thai Phase III HIV Type 1 Vaccine Trial (RV144) Regimen Induces Antibodies That Target Conserved Regions Within the V2 Loop of Gp120. AIDS Res Hum Retroviruses (2012) 28:1444-57. doi: 10.1089/aid.2012.0103

8. Rerks-Ngarm S, Pitisuttithum P, Nitayaphan S, Kaewkungwal J, Chiu J, Paris R, et al. Vaccination With ALVAC and AIDSVAX to Prevent HIV-1 Infection in Thailand. N Engl J Med (2009) 361:2209-20. doi: 10.1056/NEJMoa0908492

9. Lin A, Balazs AB. Adeno-Associated Virus Gene Delivery of Broadly Neutralizing Antibodies as Prevention and Therapy Against HIV-1 11 Medical and Health Sciences 1103 Clinical Sciences 11 Medical and Health Sciences 1108 Medical Microbiology Marit Van Gils, M.J.Vangils@Amc. Retrovirology (2018) 15:66. doi: 10.1186/s12977-018-0449-7

10. Marcotte H, Hammarström L. Passive Immunization. In: Mucosal Immunology. Elsevier: Cambridge, Massachusetts, United States (2015). 2:1403-34. doi: 10.1016/B978-0-12-415847-4.00071-9

11. Burton DR, Hangartner L. Broadly Neutralizing Antibodies to HIV and Their Role in Vaccine Design. Annu Rev Immunol (2016) 34:635-59. doi: 10.1146/ annurev-immunol-041015-055515

12. Bhiman JN, Lynch RM. Broadly Neutralizing Antibodies as Treatment: Effects on Virus and Immune System. Curr HIV/AIDS Rep (2017) 14:54-62. doi: 10.1007/s11904-017-0352-1

\section{ACKNOWLEDGMENTS}

We thank H. Marcotte (Karolinska Institute) for the donation of the CAP256 VH-VL L1 scFv. We thank the AIDS Reagent Program, Division of AIDS, NIAID, NIH, for the use of the pCMVR vector and the pBR322-based IG-lambda expression vector. We also thank J. Mascola, the VRC, USA, for the donation of the PGT121 heavy- and light-chain plasmids.

\section{SUPPLEMENTARY MATERIAL}

The Supplementary Material for this article can be found online at: https://www.frontiersin.org/articles/10.3389/fimmu.2021. 734110/full\#supplementary-material

13. Crowell TA, Colby DJ, Pinyakorn S, Sacdalan C, Pagliuzza A, Intasan J, et al. Safety and Efficacy of VRC01 Broadly Neutralising Antibodies in Adults With Acutely(RV397): A Phase 2, Randomised, Double-Blind, Placebo-Controlled Trial. Lancet HIV (2019) 6:e297-306. doi: 10.1016/S2352-3018(19)30053-0

14. Huang Y, Naidoo L, Zhang L, Carpp LN, Rudnicki E, Randhawa A, et al. Pharmacokinetics and Predicted Neutralisation Coverage of VRC01 in HIVUninfected Participants of the Antibody Mediated Prevention (AMP) Trials. EBioMedicine (2021) 64:103203. doi: 10.1016/j.ebiom.2020.103203

15. Edupuganti S, Mgodi N, Karuna ST, Andrew P, Rudnicki E, Kochar N, et al. Feasibility and Successful Enrollment in a Proof-Of-Concept HIV Prevention Trial of VRC01, a Broadly Neutralizing HIV-1 Monoclonal Antibody. J Acquir Immune Defic Syndr (2021) 87:671-9. doi: 10.1097/QAI.0000000000002639

16. Mgodi NM, Takuva S, Edupuganti S, Karuna S, Andrew P, Lazarus E, et al. A Phase $2 b$ Study to Evaluate the Safety and Efficacy of VRC01 Broadly Neutralizing Monoclonal Antibody in Reducing Acquisition of HIV-1 Infection in Women in Sub-Saharan Africa. JAIDS J Acquir Immune Defic Syndr (2021) 87:680-7. doi: 10.1097/QAI.0000000000002649

17. Corey L, Gilbert PB, Juraska M, Montefiori DC, Morris L, Karuna ST, et al. Two Randomized Trials of Neutralizing Antibodies to Prevent HIV-1 Acquisition. N Engl J Med (2021) 384:1003-14. doi: 10.1056/nejmoa2031738

18. Wagh K, Bhattacharya T, Williamson C, Robles A, Bayne MG, Garrity J, et al. Optimal Combinations of Broadly Neutralizing Antibodies for Prevention and Treatment of HIV-1 Clade C Infection. PloS Pathog (2016) 12:e1005520. doi: 10.1371/journal.ppat.1005520

19. Kong R, Louder MK, Wagh K, Bailer RT, DeCamp A, Greene KM, et al. Improving Neutralization Potency and Breadth by Combining Broadly Reactive HIV-1 Antibodies Targeting Major Neutralization Epitopes. J Virol (2015) 89:2659-71. doi: 10.1128/JVI.03136-14

20. Wagh K, Seaman MS, Zingg M, Fitzsimons T, Barouch DH, Burton DR, et al. Potential of Conventional \& Bispecific Broadly Neutralizing Antibodies for Prevention of HIV-1 Subtype A, C \& D Infections. PloS Pathog (2018) 14: e1006860. doi: 10.1371/journal.ppat.1006860

21. CAPRISA. CAPRISA Studies | CAPRISA (2020). Available at: https://www. caprisa.org/Pages/CAPRISAStudies (Accessed September 3, 2020).

22. Mahomed S, Garrett N, Karim QA, Yende-Zuma N, Capparelli E, Baxter C, et al. Assessing the Safety and Pharmacokinetics of the Anti-HIV Monoclonal Antibody CAP256V2LS Alone and in Combination With VRC07-523LS and PGT121 in South African Women: Study Protocol for the First-in-Human CAPRISA 012B Phase I Clinical Trial. BMJ Open (2020) 10:e042247. doi: 10.1136/bmjopen-2020-042247

23. Karuna ST. Phase 1 Broadly Neutralizing Antibody Efforts(2021). Available at: https:/www.hvtn.org/en/community/community-compass/vol20-issue1/ phase-1-broadly-neutralizing-antibody-efforts.html (Accessed April 2, 2021).

24. Karuna ST, Corey L. Broadly Neutralizing Antibodies for HIV Prevention. Annu Rev Med (2020) 71:329-46. doi: 10.1146/annurev-med-110118-045506

25. Foucquier J, Guedj M. Analysis of Drug Combinations: Current Methodological Landscape. Pharmacol Res Perspect (2015) 3:e00149. doi: $10.1002 /$ prp2.149 
26. Davis-Gardner ME, Alfant B, Weber JA, Gardner MR, Farzan M. A Bispecific Antibody That Simultaneously Recognizes the V2-And V3-Glycan Epitopes of the Hiv-1 Envelope Glycoprotein is Broader and More Potent Than Its Parental Antibodies. MBio (2020) 11(1):e03080-19. doi: 10.1128/ mBio.03080-19

27. Huang Y, Yu J, Lanzi A, Yao X, Andrews CD, Tsai L, et al. Engineered Bispecific Antibodies With Exquisite HIV-1-Neutralizing Activity. Cell (2016) 165:1621-31. doi: 10.1016/j.cell.2016.05.024

28. Khan SN, Sok D, Tran K, Movsesyan A, Dubrovskaya V, Burton DR, et al. Targeting the HIV-1 Spike and Coreceptor With Bi- and Trispecific Antibodies for Single-Component Broad Inhibition of Entry. J Virol (2018) 92(18):e00384-18. doi: 10.1128/jvi.00384-18

29. West AP, Galimidi RP, Gnanapragasam PNP, Bjorkman PJ. Single-Chain FvBased Anti-HIV Proteins: Potential and Limitations. J Virol (2012) 86:195202. doi: 10.1128/JVI.05848-11

30. Song R, Pace C, Seaman MS, Fang Q, Sun M, Andrews CD, et al. Distinct HIV-1 Neutralization Potency Profiles of Ibalizumab-Based Bispecific Antibodies. J Acquir Immune Defic Syndr (2016) 73:365-73. doi: 10.1097/ QAI.0000000000001119

31. Moshoette T, Ali SA, Papathanasopoulos MA, Killick MA. Engineering and Characterising a Novel, Highly Potent Bispecific Antibody Imab-CAP256 That Targets HIV-1. Retrovirology (2019) 16:1-12. doi: 10.1186/s12977-0190493-y

32. Colcher D, Pavlinkova G, Beresford G, Booth BJ, Choudhury A, Batra SK. Pharmacokinetics and Biodistribution of Genetically-Engineered Antibodies (1998). Available at: https://search.proquest.com/openview/ aad $96 \mathrm{f} 81 \mathrm{lb} 8 \mathrm{e} 44830 \mathrm{fd} 2 \mathrm{f} 5817 \mathrm{ff} 5 \mathrm{~b} 54 \mathrm{~b} / 1$ ? pq-origsite $=$ gscholar\&cbl $=27900$ (Accessed August 14, 2018).

33. Unverdorben F, Richter F, Hutt M, Seifert O, Malinge P, Fischer N, et al. Pharmacokinetic Properties of IgG and Various Fc Fusion Proteins in Mice. MAbs (2016) 8:120-8. doi: 10.1080/19420862.2015.1113360

34. Yokota T, Milenic DE, Whitlow M, Schlom J. Rapid Tumor Penetration of a Single-Chain Fv and Comparison With Other Immunoglobulin Forms. Cancer Res (1992) 52:3402-8. doi: 10.1007/s00429-013-0597-4

35. Unverdorben F, Färber-Schwarz A, Richter F, Hutt M, Kontermann RE. HalfLife Extension of a Single-Chain Diabody by Fusion to Domain B of Staphylococcal Protein A. Protein Eng Des Sel (2012) 25:81-8. doi: 10.1093/ protein/gzr061

36. Kumar S, Kumar R, Khan L, Makhdoomi MA, Thiruvengadam R, Mohata M, et al. CD4-Binding Site Directed Cross-Neutralizing scFv Monoclonals From HIV-1 Subtype C Infected Indian Children. Front Immunol (2017) 8:1568. doi: 10.3389/fimmu.2017.01568

37. Alam MMM, Kuwata T, Tanaka K, Alam MMM, Takahama S, Shimura K, et al. Synergistic Inhibition of Cell-to-Cell HIV-1 Infection by Combinations of Single Chain Variable Fragments and Fusion Inhibitors. Biochem Biophys Rep (2019) 20:100687. doi: 10.1016/j.bbrep.2019.100687

38. van Dorsten RT, Lambson BE, Wibmer CK, Weinberg MS, Moore PL, Morris L. Neutralization Breadth and Potency of Single-Chain Variable Fragments Derived From Broadly Neutralizing Antibodies Targeting Multiple Epitopes on the HIV-1 Envelope. J Virol (2020) 94(2):e01533-19. doi: 10.1128/ JVI.01533-19

39. Portolano N, Watson PJ, Fairall L, Millard CJ, Milano CP, Song Y, et al. Recombinant Protein Expression for Structural Biology in HEK 293F Suspension Cells: A Novel and Accessible Approach. J Vis Exp (2014) 92: e51897. doi: 10.3791/51897

40. Gasteiger E, Hoogland C, Gattiker A, Duvaud S, Wilkins MR, Appel RD, et al. Protein Identification and Analysis Tools on the ExPASy Server. In: The Proteomics Protocols Handbook. Totowa, NJ: Humana Press (2005). 571-607. doi: 10.1385/1-59259-890-0:571

41. Gray ES, Madiga MC, Hermanus T, Moore PL, Wibmer CK, Tumba NL, et al. The Neutralization Breadth of HIV-1 Develops Incrementally Over Four Years and Is Associated With CD4+ T Cell Decline and High Viral Load During Acute Infection. J Virol (2011) 85:4828-40. doi: 10.1128/JVI.00198-11

42. Doria-Rose NA, Schramm CA, Gorman J, Moore PL, Bhiman JN, DeKosky BJ, et al. Developmental Pathway for Potent V1V2-Directed HIVNeutralizing Antibodies. Nature (2014) 509:55-62. doi: 10.1038/nature13036
43. Moore PL, Sheward DJ, Nonyane M, Ranchobe N, Hermanus T, Gray ES, et al. Multiple Pathways of Escape From HIV Broadly Cross-Neutralizing V2Dependent Antibodies. J Virol (2013) 87:4882-94. doi: 10.1128/JVI.03424-12

44. Todd CA, Greene KM, Yu X, Ozaki DA, Gao H, Huang Y, et al. Development and Implementation of an International Proficiency Testing Program for a Neutralizing Antibody Assay for HIV-1 in TZM-Bl Cells. J Immunol Methods (2012) 375:57-67. doi: 10.1016/j.jim.2011.09.007

45. Sarzotti-Kelsoe M, Bailer RT, Turk E, li LC, Bilska M, Greene KM, et al. Optimization and Validation of the TZM-Bl Assay for Standardized Assessments of Neutralizing Antibodies Against HIV-1. J Immunol Methods (2014) 409:131-46. doi: 10.1016/j.jim.2013.11.022

46. Mascola JR, D'Souza P, Gilbert P, Hahn BH, Haigwood NL, Morris L, et al. Recommendations for the Design and Use of Standard Virus Panels To Assess Neutralizing Antibody Responses Elicited by Candidate Human Immunodeficiency Virus Type 1 Vaccines. J Virol (2005) 79:10103-7. doi: 10.1128/jvi.79.16.10103-10107.2005

47. Rujas E, Caaveiro JMM, Partida-Hanon A, Gulzar N, Morante K, Apellániz B, et al. Structural Basis for Broad Neutralization of HIV-1 Through the Molecular Recognition of 10E8 Helical Epitope at the Membrane Interface. Sci Rep (2016) 6:1-13. doi: 10.1038/srep38177

48. Wang Y, Kaur P, Sun Z-YJ, Elbahnasawy MA, Hayati Z, Qiao Z-S, et al. Topological Analysis of the Gp41 MPER on Lipid Bilayers Relevant to the Metastable HIV-1 Envelope Prefusion State. Proc Natl Acad Sci (2019) 116:22556-66. doi: 10.1073/PNAS.1912427116

49. Fu Q, Shaik MM, Cai Y, Ghantous F, Piai A, Peng H, et al. Structure of the Membrane Proximal External Region of HIV-1 Envelope Glycoprotein. Proc Natl Acad Sci (2018) 115:E8892-9. doi: 10.1073/pnas.1807259115

50. Kim AS, Leaman DP, Zwick MB. Antibody to Gp41 MPER Alters Functional Properties of HIV-1 Env Without Complete Neutralization. PloS Pathog (2014) 10:e1004271. doi: 10.1371/JOURNAL.PPAT.1004271

51. Pinto D, Fenwick C, Caillat C, Silacci C, Guseva S, Dehez F, et al. Structural Basis for Broad HIV-1 Neutralization by the MPER-Specific Human Broadly Neutralizing Antibody Ln01. Cell Host Microbe (2019) 26:623-37.e8. doi: $10.1016 /$ j.chom.2019.09.016

52. Zhou T, Doria-Rose NA, Cheng C, Stewart-Jones GBE, Chuang G-Y, Chambers $\mathrm{M}$, et al. Quantification of the Impact of the HIV-1-Glycan Shield on Antibody Elicitation. Cell Rep (2017) 19:719-32. doi: 10.1016/j.celrep.2017.04.013

53. Doria-Rose NA, Bhiman JN, Roark RS, Schramm CA, Gorman J, Chuang GY, et al. New Member of the V1V2-Directed CAP256-VRC26 Lineage That Shows Increased Breadth and Exceptional Potency. J Virol (2015) 90:76-91. doi: 10.1128/JVI.01791-15

54. Lorenzi JCC, Mendoza P, Cohen YZ, Nogueira L, Lavine C, Sapiente J, et al. Neutralizing Activity of Broadly Neutralizing Anti-HIV-1 Antibodies Against Primary African Isolates. J Virol (2021) 95(5):e01909-20. doi: 10.1128/ jvi.01909-20

55. Cohen YZ, Lorenzi JCC, Seaman MS, Nogueira L, Schoofs T, Krassnig L, et al. Neutralizing Activity of Broadly Neutralizing Anti-HIV-1 Antibodies Against Clade B Clinical Isolates Produced in Peripheral Blood Mononuclear Cells. J Virol (2017) 92:e01883-17. doi: 10.1128/JVI.01883-17

56. Liu Q, Lai YT, Zhang P, Louder MK, Pegu A, Rawi R, et al. Improvement of Antibody Functionality by Structure-Guided Paratope Engraftment. Nat Commun (2019) 10:741. doi: 10.1038/s41467-019-08658-4

57. Rosenberg YJ, Lewis GK, Montefiori DC, LaBranche CC, Lewis MG, Urban LA, et al. Introduction of the YTE Mutation Into the Non-Immunogenic HIV bnAb PGT121 Induces Anti-Drug Antibodies in Macaques. PloS One (2019) 14:e0212649. doi: 10.1371/journal.pone.0212649

58. van den Berg FT, Makoah NA, Ali SA, Scott TA, Mapengo RE, Mutsvunguma LZ, et al. AAV-Mediated Expression of Broadly Neutralizing and VaccineLike Antibodies Targeting the HIV-1 Envelope V2 Region. Mol Ther Methods Clin Dev (2019) 14:100-12. doi: 10.1016/j.omtm.2019.06.002

59. Brady JM, Baltimore D, Balazs AB. Antibody Gene Transfer With AdenoAssociated Viral Vectors as a Method for HIV Prevention. Immunol Rev (2017) 275:324-33. doi: 10.1111/imr.12478

60. Monnier P, Vigouroux R, Tassew N. In Vivo Applications of Single Chain Fv (Variable Domain) (scFv) Fragments. Antibodies (2013) 2:193-208. doi: $10.3390 /$ antib2020193 
61. Hay CE, Gonzalez GA, Ewing LE, Reichard EE, Hambuchen MD, NanawareKharade N, et al. Development and Testing of AAV-Delivered Single-Chain Variable Fragments for the Treatment of Methamphetamine Abuse. PloS One (2018) 13:e0200060. doi: 10.1371/journal.pone.0200060

62. Gruenert AK, Czugala M, Mueller C, Schmeer M, Schleef M, Kruse FE, et al. Self-Complementary Adeno-Associated Virus Vectors Improve Transduction Efficiency of Corneal Endothelial Cells. PloS One (2016) 11:e0152589. doi: 10.1371/journal.pone.0152589

63. Dong J-Y, Fan P-D, Frizzell RA. Quantitative Analysis of the Packaging Capacity of Recombinant Adeno-Associated Virus. Hum Gene Ther (2008) 7:2101-12. doi: 10.1089/hum.1996.7.17-2101

64. Wu Z, Yang H, Colosi P. Effect of Genome Size on AAV Vector Packaging. Mol Ther (2010) 18:80-6. doi: 10.1038/mt.2009.255

65. Liu Z, Chen O, Wall JBJ, Zheng M, Zhou Y, Wang L, et al. Systematic Comparison of 2A Peptides for Cloning Multi-Genes in a Polycistronic Vector. Sci Rep (2017) 7:2193. doi: 10.1038/s41598-017-02460-2

66. Raj D, Davidoff AM, Nathwani AC. Self-Complementary Adeno-Associated Viral Vectors for Gene Therapy of Hemophilia B: Progress and Challenges. Expert Rev Hematol (2011) 4:539-49. doi: 10.1586/ehm.11.48

67. Patel P, Kriz J, Gravel M, Soucy G, Bareil C, Gravel C, et al. Adeno-Associated Virus-Mediated Delivery of a Recombinant Single-Chain Antibody Against Misfolded Superoxide Dismutase for Treatment of Amyotrophic Lateral Sclerosis. Mol Ther (2014) 22:498-510. doi: 10.1038/mt.2013.239

68. Krishnaswamy S, Huang HW, Marchal IS, Ryoo HD, Sigurdsson EM. Neuronally Expressed Anti-Tau scFv Prevents Tauopathy-Induced Phenotypes in Drosophila Models. Neurobiol Dis (2020) 137:104770. doi: $10.1016 /$ j.nbd.2020.104770

69. Morita S, Noguchi H, Horii T, Nakabayashi K, Kimura M, Okamura K, et al. Targeted DNA Demethylation In Vivo Using Dcas9-Peptide Repeat and scFvTET1 Catalytic Domain Fusions. Nat Biotechnol (2016) 34:1060-5. doi: $10.1038 /$ nbt.3658
70. Phoolcharoen W, Banyard AC, Prehaud C, Selden D, Wu G, Birch CPD, et al. In Vitro and In Vivo Evaluation of a Single Chain Antibody Fragment Generated in Planta With Potent Rabies Neutralisation Activity. Vaccine (2019) 37:4673-80. doi: 10.1016/j.vaccine.2018.02.057

71. Greineder CF, Villa CH, Walsh LR, Kiseleva RY, Hood ED, Khoshnejad M, et al. Site-Specific Modification of Single-Chain Antibody Fragments for Bioconjugation and Vascular Immunotargeting. Bioconjug Chem (2018) 29:56-66. doi: 10.1021/acs.bioconjchem.7b00592

72. Rafiq S, Yeku OO, Jackson HJ, Purdon TJ, van Leeuwen DG, Drakes DJ, et al. Targeted Delivery of a PD-1-Blocking scFV by CAR-T Cells Enhances AntiTumor Efficacy In Vivo. Nat Biotechnol (2018) 36:847-58. doi: 10.1038/ nbt.4195

Conflict of Interest: The authors declare that the research was conducted in the absence of any commercial or financial relationships that could be construed as a potential conflict of interest.

Publisher's Note: All claims expressed in this article are solely those of the authors and do not necessarily represent those of their affiliated organizations, or those of the publisher, the editors and the reviewers. Any product that may be evaluated in this article, or claim that may be made by its manufacturer, is not guaranteed or endorsed by the publisher.

Copyright (c) 2021 van Dorsten, Wagh, Moore and Morris. This is an open-access article distributed under the terms of the Creative Commons Attribution License (CC BY). The use, distribution or reproduction in other forums is permitted, provided the original author(s) and the copyright owner(s) are credited and that the original publication in this journal is cited, in accordance with accepted academic practice. No use, distribution or reproduction is permitted which does not comply with these terms. 